\title{
La caza y su régimen normativo
}

\author{
Victor Manteca Valdelande \\ Doctor en Derecho
}

\section{INTRODUCCIÓN}

El presente trabajo examina el régimen jurídico de la caza en España las competencias administrativas, la regulación de la propia actividad cinegética, el régimen de vigilancia así como el sistema de infracciones junto con otros aspectos no menos importantes como el seguro obligatorio de responsabilidad civil, la protección de la caza.

\section{COMPETENCIAS ADMINISTRATIVAS EN MATERIA DE CAZA}

La Constitución española regula esta materia en su artículo 148.1.11 a como una actividad de competencia exclusiva de las Comunidades Autónomas, no obstante, como veremos, el Estado retiene una pluralidad de títulos competenciales que le permiten incidir en la regulación de esta materia y que, por tanto, condicionan y restringen el alcance de la competencia autonómica en materia de caza.

La Unión Europea además actúa también en la protección del medio ambiente a lo que hay que añadir la normativa internacional que sobre esta misma materia es de aplicación en España. Todo esto tiene una incidencia notable en el régimen de la caza.

El Estado pues dispone de potestades para regular normativa básica que restringen -de hecho- el alcance de la competencia de las Comunidades Autónomas sobre la caza, siendo el Ministerio de Medio Ambiente el Departamento estatal con competencias en esta materia. Hay que señalar que la respuesta de las Comunidades Autónomas a la atribución de la caza como competencia autonómica si bien se ha plasmado en los Estatutos de Autonomía, en lo que se refiere a las leyes de desarrollo ha sido diversa: hay leyes de caza, leyes de protección de la fauna silvestre e, incluso leyes de protección de los animales, a través de las que indirecta y solapadamente se incide en la caza. 
Con todo la mayor parte de las Comunidades Autónomas no han desarrollado aún una normativa cinegética propia, sino que se han limitado a regular aspectos concretos o a aplicar la normativa estatal. Esto quiere decir que actualmente la Ley 1/1970 de 4 de abril de caza sigue siendo de aplicación, con carácter supletorio, en la gran parte del territorio nacional en la medida en que las Comunidades Autónomas no dispongan de normativa específica.

\section{LA PROTECCIÓN DEL MEDIO NATURAL}

De acuerdo con el artículo 149.1.23 de la Constitución, el Estado tiene competencia para dictar la legislación básica sobre protección del medio ambiente, pudiendo las Comunidades Autónomas desarrollar esta normativa básica estatal. La razón de esta atribución estatal tiene su explicación en la conveniencia de que las líneas fundamentales de la ordenación jurídica de esta materia se fijen a nivel nacional de manera que todas las Comunidades Autónomas han asumido en sus estatutos de autonomía el espacio que les deja la Constitución, por lo que esta disposición establece además el techo competencial del propio Estado.

El artículo 149.1.23 $3^{\underline{a}}$ de la Constitución permite al Estado dictar legislación básica en materia de protección de la fauna silvestre incidiendo con ello en el régimen de la caza, lo cual ha sido confirmado por el Tribunal Constitucional que ha declarado que los recursos naturales pueden ser regulados desde variadas perspectivas entre ellas la medioambiental, ${ }^{1}$ y que el alcance de esta competencia ha de entenderse para emanar normativa básica lo que permite al Estado dictar tanto leyes como normas de carácter reglamentario. Por otra parte también ha declarado que en la competencia estatal se halla incluida la capacidad para que el Estado emane actos meramente ejecutivos. ${ }^{2}$

\footnotetext{
${ }^{1}$ Sentencia 102/1995 de 31 de julio fundamentos Jurídicos $6^{\circ}$ y $7^{\circ}$. Hay que mencionar el voto particular a esta sentencia de Rafael Mendizábal Allende quien subrayó la dimensión formal que acompaña a la expresión constitucional legislación básica, frente al carácter material propio de la expresión bases. Ello lleva a exigir el rango legal para la intervención del Estado en esta materia La consecuencia sería -en opinión de Mendizábal- que por esta razón la normativa raglamentaria de desarrollo de la Ley de conservación de los espacios naturales y de la flora y fauna silvestre pierde toda cobertura constitucional, así como desaparecería la posibilidad de que el Estado interviniera con fundamento en esta disposición, mediante actos ejecutivos.

${ }^{2}$ Como veremos la Ley de conservación de los espacios y de la flora y fauna silvestres está desarrollada por una serie de reales decretos con una incidencia efectiva en el régimen de la caza.

STS. 1491991 de 4 de julio, 149/1991 de 4 de julio, 135/1992 de 5 de octubre y 329/1993 de 12 de noviembre.
} 
Con este fundamento se aprobó la Ley 4/1989 de Conservación de los espacios naturales y de la flora y fauna silvestres ${ }^{3}$, cuyos preceptos condicionan en aspectos importantes el régimen jurídico de la caza en España.

El Título IV de esta ley regula la protección de la fauna silvestre condicionando la, competencia autonómica en materia de caza y pesca al tener que someterse esta a la legislación básica estatal. Con todo, hay que tener en cuenta que la actuación del Estado, basada en la competencia en materia de medio ambiente, solo llega hasta la legislación básica mientras que la caza corresponde a las Comunidades Autónomas muchos de cuyos Estatutos de Autonomía extienden esta competencia autonómica, a la función protectora de los ecosistemas en los que se desarrollen.

En relación con la protección de especies frente a la caza el Tribunal Constitucional ha admitido la constitucionalidad del artículo 33 de la Ley que prevé la determinación normativa de las piezas susceptibles de ser cazadas, la regulación del ejercicio de la caza, de modo que quede garantizada la conservación y fomento de las especies con determinación de los terrenos y periodos cinegéticos y la exigencia de un plan justificativo de la cuantía y modalidades de capturas, a fin de proteger la fauna silvestre ${ }^{4}$.

Como desarrollo de la Ley de conservación de 1989 el Estado ha venido aprobando disposiciones de protección de la fauna silvestre como el Real Decreto 1997/1995 para garantizar la biodiversidad mediante la conservación de hábitats naturales y de la fauna y flora silvestres ${ }^{5}$.

\footnotetext{
${ }^{3}$ Ley 4/1989 de 27 de marzo de conservación de los espacios naturales y de la flora y fauna silvestres (BOE núm 74 de 28 de marzo de 1989).

${ }^{4}$ El Tribunal Constitucional considera incluidas asimismo en la competencia estatal sobre medio ambiente una serie de preceptos contenidos en el artículo 34 de la Ley de espacios naturales relativos a procedimientos de caza, la introducción de especies, su comercialización, así como prohibiciones del ejercicio de la caza en base a su supervivencia, y para la previsión del Censo $\mathrm{Na}$ cional de Caza y Pesca y del Registro Nacional de Infractores de Caza y Pesca.(STC 102/1995.

${ }^{5}$ Como transposición parcial de la Directiva Europea 92/43 CEE del CONSEJO de 21 de mayo de 1992 relativa ala conservación de los hábitats y de la fauna y flora silvestres. DOCE 1 206/8 DE 22.7.92.

La Disposición adicional primera del Real Decreto 1997/1995 declara que se dicta al amparo del artículo 149.1.23 ${ }^{\underline{a}}$ de la Constitución, el preámbulo del mismo aclara asimismo que se dicta con carácter básico, salvo en lo relativo a los métodos de caza cuya transposición se realiza para garantizar el cumplimiento del derecho derivado europeo.
} 
La potestad sancionadora contenida el la Ley de conservación (Título VI) y sus tipificaciones básicas tienen carácter mínimo, permitiéndose a las Comunidades Autónomas desarrollar este aspecto.

Además hay que recordar que el Estado es competente para la regulación de los aspectos civiles que acompañan a la actividad cinegética ${ }^{6}$ en este sentido la adquisición de las piezas de caza, que tiene lugar mediante ocupación, o el régimen de responsabilidad civil del cazador se rigen por normas de Derecho privado.

Por otro lado la ordenación jurídica de la caza tiene una faceta penal prevista por la propia Constitución ${ }^{7}$ que hace que las infracciones más graves sean constitutivas de delitos tipificados en el Código Penal.

Por otra parte, el Estado tiene competencia exclusiva en materia de armas, que constituyen el instrumento esencial para llevar a cabo la actividad de caza $^{8}$, en materia de relaciones internacionales y sanidad exterior ${ }^{9}$, siendo el conjunto de estas competencias lo que ha permitido al Estado la aprobación del Real Decreto 2044/1994 de 14 de octubre que establece con carácter básico las condiciones sanitarias y de sanidad animal aplicables al sacrificio de animales de caza silvestre y a la producción y comercialización de sus carnes. ${ }^{10}$

\footnotetext{
${ }^{6}$ Artículo $149.18^{\underline{a}}$ de la Constitución.

${ }^{7}$ Artículo 45.3.

${ }^{8}$ Así se dispone en el artículo 149.126 a de la Constitución que le reserva la competencia para establecer el régimen de producción, comercio, tenencia y uso de armas y explosivos. La legislación específica sobre esta materia está constituida por el Real Decreto 137/1993, de 29 de enero que aprobó el Reglamento de Armas ( las sentencias del Tribunal Supremo de 28 de enero de 1994 y de 9 de diciembre de 1994 declaran la falta de cobertura legal de algunas infracciones y sanciones previstas en este Reglamento), y por el Real decreto 2283/1985 de 4 de diciembre por el que se regula la emisión de los informes de aptitud necesarios para la obtención de licencias, permisos y tarjetas de armas. Por orden del Ministerio de la Presidencia del Gobierno de 20 de julio de 1994 se lleva a cabo la actualización de las tarifas aplicables a por el reconocimiento y emisión de los informes de aptitud para la tenencia y uso de armas.

${ }^{9}$ Para la firma de Tratados internacionales y acuerdos relativos a la protección de la fauna silvestre y la caza y como especificidad de esta competencia internacional del Estado, el artículo 149.1.10 $0^{\underline{a}}$ le atribuye al la responsabilidad exclusiva en materia de comercio exterior en el que se incluye el de piezas de caza. La sanidad exterior se encuentra atribuida al Estado por el artículo 149.1.16ª que la Ley Orgánica 3/1986 de 14 de abril de Salud Pública concreta y determina.

${ }^{10}$ El real decreto 1543/1994 de 8 de julio establece los requisitos sanitarios y de policía sanitaria aplicables a la producción y comercialización de carne de conejo y caza de granja.
} 


\section{COMPETENCIA DE LAS COMUNIDADES AUTÓNOMAS EN MATERIA CINEGÉTICA}

Como podemos deducir del apartado anterior la caza se configura como un título competencial independiente diferente del de medio ambiente y recursos naturales, de competencia de las Comunidades Autónomas. En este sentido podemos decir que las competencias del Estado terminan donde empiezan las de las Comunidades Autónomas. No obstante las competencias del Estado en materia de caza han tenido que ser precisadas por el Tribunal Constitucional $^{11}$. Así en el caso de las licencias de caza el Tribunal ha negado al Estado competencia para imponer un examen de aptitud o idoneidad al resultar rebasada la materia de medio ambiente, posibilitando por otra parte que las licencias puedan tener un ámbito de validez superior al autonómico mediante acuerdos de reciprocidad, etc.

En relación con las especies cazables establecido en el Real Decreto 1095/1989 de 8 de septiembre, el Tribunal ha declarado que se consideraría básico el establecimiento de directrices para que las relaciones de especies pudieran ser confeccionadas, pero no la aprobación de una relación única nacional, con contenido tan concreto como se establece en el Real Decreto citado.

Respecto a la especificación de los procedimientos de caza masivos no selectivos ${ }^{12}$ y determinación de los periodos hábiles de caza ${ }^{13}$ el Tribunal ha declarado que lo básico, por su contenido genérico y mínimo - es la escueta previsión de la Ley pero no la reglamentaria por que sale del marco de la protección de la fauna para invadir el campo de la caza.

Las Comunidades Autónomas tienen atribuida la competencia en materia de caza y han asumido en sus respectivos Estatutos de Autonomía estas competencias, no obstante en lo que respecta a la normativa de regulación su actitud ha sido variada y desigual, pues en algunos casos se han aprobado leyes de caza; en otros, leyes de protección de la fauna silvestre, otras veces se

\footnotetext{
11 STC 102/1995 de 26 de junio.

12 Que establece el artículo 34 de la Ley 4/1989 y a partir de esta previsión legal el Real Decreto 1095/1989 en su artículo 3.1 especifica los procedimientos de caza masivos que se entienden prohibidos, los cuales aparecen relacionados en su anexo III que por disposición adicional es considerado básico.
} 
han regulado algunos aspectos de la caza a través de leyes de protección de los animales y en otros supuestos se han limitado o bien a desarrollo aspectos concretos de la normativa del Estado o simplemente a aplicarla.

Hemos de adelantar que la legislación estatal sobre caza ${ }^{14}$, sigue siendo de aplicación en gran parte de las Comunidades Autónomas. Si bien es previsible que el panorama normativo autonómico se complete con el tiempo, hay que reconocer que las normas autonómicas sobre caza se han beneficiado de la técnica normativa constituida por la Ley de caza de 1970 y su Reglamento de desarrollo cuya huella aparece en las normas autonómicas que han ido aprobándose.

\section{CAPACIDAD JURÍDICA PARA EJERCER LA CAZA}

El elemento subjetivo del derecho de caza es el cazador. El ejercicio de la actividad de caza requiere una serie de condiciones de capacidad, que la Administración debe reconocer formalmente mediante la emisión de las correspondientes autorizaciones administrativas ${ }^{15}$. Por ello podemos definir al cazador como la persona que practica la caza reuniendo los requisitos para ello ${ }^{16}$. Si bien la Ley exige la edad de catorce años, hay que puntualizar que el me-

\footnotetext{
13 El artículo 32.2 de la Ley 4/1989 encomienda a la Administración la determinación de las fechas hábiles en que puede cazarse cada especie como medio para garantizar su conservación y fomento al tiempo que el artículo 34 b) prohíbe el ejercicio de la caza durante las épocas de celo, reproducción y crianza, así como en su trayecto de regreso hacia los lugares de cría, en caso de las especies migratorias. En desarrollo de estos preceptos el Real Decreto 1095/1989 fijó los que se consideran periodos de regreso hasta los lugares de reproducción de las especies cinegéticas migratorias.
}

${ }^{14}$ Por la vía de la aplicación supletoria del Derecho del Estado.

Constitución art. 149.3 "Las materias no atribuidas expresamente al Estado por esta Constitución podrán corresponder a las Comunidades Autónomas, en virtud de sus respectivos estatutos. La competencia sobre las materias que no se hayan asumido por los Estatutos de Autonomía corresponderá al Estado, cuyas normas prevalecerán, en caso de conflicto, sobre las de las Comunidades Autónomas en todo lo que no esté atribuido a la exclusiva competencia de éstas. El derecho estatal será, en todo caso, supletorio del derecho de las Comunidades Autónomas."

\footnotetext{
${ }^{15}$ La declaración de esta capacidad reconoce al ciudadano particular una situación que podemos calificar de derecho público subjetivo que la emisión de la licencia reconoce.

${ }^{16}$ El artículo 3.1 de la Ley 1/1970 dispone "El derecho a cazar corresponde a toda persona mayor de catorce años que esté en posesión de la licencia de caza y cumpla los demás requisitos establecidos en la presente Ley".
} 
nor de edad precisará de la autorización escrita de su representante legal además para cazar con armas de fuego es preciso haber alcanzado la mayoría de edad o ir acompañado por cazadores mayores de edad ${ }^{17}$.

En definitiva se exige que el particular no se encuentre inhabilitado por sentencia judicial o resolución administrativa firma que entrañe la retirada de la licencia o la imposibilidad de obtenerla durante un periodo de tiempo.

Elemento objetivo del derecho de caza es la acción de cazar que en el artículo 2 de la Ley de caza se considera a la acción ejercida por el hombre mediante el uso de artes o medios apropiados para buscar, atraer, perseguir o acosar a los animales definidos por la Ley como piezas de caza con el fin de darles muerte, apropiarse de ellos o de facilitar su captura por tercero. En algunas leyes autonómicas sobre caza se ha excluido expresamente de la acción de cazar a la realizada por quienes asistan a las cacerías realizando labores meramente auxiliares ${ }^{18}$.

Como elemento formal del derecho de caza hacemos mención a una serie de exigencias administrativas a las que se supedita la habilitación para cazar, esto es la licencia de caza y la Licencia de armas.

\section{La licencia de caza}

La licencia de caza habilita al particular para su ejercicio, previa comprobación de que el individuo reúne las condiciones exigidas por la normativa, con esta óptica la licencia tiene fines tanto de seguridad como de protección de la fauna silvestre ${ }^{19}$.

La licencia de caza es una exigencia que contiene de manera implícita la Ley 4/1989 de conservación de los espacios naturales y de la flora y fauna sil-

\footnotetext{
${ }^{17}$ Artículos 3.3 y 31.11 de la Ley 1/1970 de caza.

${ }^{18}$ El artículo 29.2 de la Ley 2/1993 de 15 de julio de Caza de Castilla-La Mancha que "No tendrán la condición de cazadores quienes asistan a las cacerías en calidad de auxiliares, no pudiendo disparar salvo con munición de fogueo".

${ }^{19}$ Antonio Royo Villanova señalaba que las licencias de uso de escopeta y caza constituyen " una limitación del derecho de ocupación en interés público” ROYO VILLANOVA A. Principios de Derecho Administrativo Valladolid 1901.
} 
vestre $^{20}$ y exige de modo expreso la Ley 1/1970 de caza que en su artículo 3.1 dispone que el derecho a cazar corresponde a toda persona mayor de catorce años que esté en posesión de la licencia de caza y cumpla los demás requisitos establecidos en la presente ley; el artículo 34.1dispone que "La licencia de caza es el documento nominal e intransferible cuya tenencia es necesaria para practicar la caza dentro del terreno nacional "además determinadas modalidades de caza requieren una licencia especial"21.

Para obtener la licencia de caza es requisito la previa presentación de un certificado expedido por el Registro Nacional de Infractores de Caza y Pesca ${ }^{22}$ esta exigencia que el Tribunal constitucional ha considerado básica se justifica en la necesidad de que la Administración pondere la peligrosidad de cada solicitante deducida de sus eventuales antecedentes que serán reflejo de su conducta y su cumplimiento de las leyes.

La realización de pruebas de aptitud previas está justificada en la protección de la fauna silvestre y en la seguridad de las personas, por otra parte también se trata de una exigencia elemental del Derecho Internacional ${ }^{23}$.

${ }^{20} \mathrm{El}$ artículo 35.2 dispone que "La superación del citado examen habilitará a los interesados para la obtención de las correspondientes licencias de caza o pesca, que expedirán los órganos competentes de las Comunidades Autónomas..."

${ }^{21}$ Artículo 34.2 de la Ley de caza "Para cazar con aves de cetrería, hurones, reclamo de perdiz macho o poseer rehalas con fines de caza será preciso estar provisto de una licencia especial".

${ }^{22}$ Artículo 35.4 de la Ley de conservación de los espacios naturales y de la flora y fauna silvestre.

El artículo 34.6 de la Ley de caza de 1970 preveía el establecimiento por la Administración de las pruebas de aptitud que considerase necesarias para el otorgamiento de la licencia de caza. El artículo 36.7 de la misma del Reglamento de 1971 precisaba que dichas pruebas versarías sobre el conocimiento de la legislación de caza, la distinción de las especies zoológicas y el correspondiente uso de armas, previendo acciones de colaboración entre la Guardia Civil y la Federación Española de Caza.

${ }^{23}$ La Recomendación R (85) 17 de 23 de septiembre, del Comité de ministros del Consejo de Europa aconseja condicionar el otorgamiento de la licencia de caza a la previa realización de unas pruebas teóricas y prácticas. (el apéndice I de la Resolución incluye una serie de recomendaciones relativas a la prueba de aptitud, sugiriendo para la teórica la comprobación del conocimiento de la fauna y sus hábitats (identificación de las especies susceptibles de caza y las protegidas); de la normativa nacional e internacional relativa a la caza y la conservación de la naturaleza; de los métodos y prácticas de caza; así como el código de conducta del cazador.

Se sugiere la realización de una prueba práctica en la que se demuestre el reconocimiento de las especies y las normas de caza. Aludiéndose a la posibilidad de someter al cazador novel a un periodo de prueba previo a la concesión definitiva de la licencia de caza. 
Todas las Comunidades Autónomas exigen la previa comprobación de los cazadores como requisito para la obtención de la licencia de caza.

La licencia de caza tal como se reguló en la Ley de 1970 produjo una controversia acerca de la naturaleza del derecho de caza, pues atendiendo a la literalidad del artículo 3-1 de la Ley, podría pensarse que la misma es un acto constitutivo no obstante gran parte de la doctrina considera que la licencia es un acto declarativo del derecho de caza, entendiéndose así que la Administración no otorga al solicitante ningún derecho que éste no tuviera ya previamente del derecho a cazar ${ }^{24}$.

La licencia de caza constituye a nuestro juicio una autorización de carácter declarativo ${ }^{25}$ por otra parte se trata de un acto administrativo reglado como se desprende de la regulación de la propia Ley de caza, por ello demostrada la capacitación personal, la Administración no cuenta con ningún margen de discrecionalidad que le permita valorar la oportunidad del otorgamiento o no de la licencia.

\section{Licencia de armas}

La práctica de la caza con armas de fuego, requiere la obtención previa de una licencia, para su tenencia y uso $^{26}$. La licencia de armas para caza sólo

La Resolución de la Comisión Permanente del Consejo de Europa 882/1987 relativa a la importancia de la caza para las regiones rurales de Europa de 1 de julio de 1987, sugiere a los Gobiernos de las Estados miembros impulsar la mejora de la formación de sus nacionales en estas materias, como modo de evitar algunos daños causados a la fauna silvestre debidos a la inexperiencia de los cazadores.

${ }^{24}$ BOQUERA OLIVER J.M. Aspectos administrativos de la Ley de caza REVISTA DE ESTUDIOS DE LA VIDA LOCAL núm. 177 pp. 34-39.

${ }^{25}$ Siguiendo a Laguna la licencia de caza sería una autorización administrativa de naturaleza meramente declarativa limitada a remover los obstáculos existentes para el ejercicio de la caza por los particulares que tienen derecho, pero por razones de interés público la norma somete al previo control y habilitación administrativa. La autorización sería una excepción a la general prohibición contenida en la Ley confiriendo potestad jurídica para ejercer un derecho del que ya era titular.

${ }^{26}$ El artículo 7.1.b) de la Ley Orgánica 1/1992 de 21 de febrero de Protección de la Seguridad Ciudadana dispone que "Se faculta al Gobierno para reglamentar las materias y actividades a que se refiere el artículo anterior, en atención a las circunstancias que puedan concurrir en los distintos supuestos:

b) Mediante la obligatoriedad de licencias o permisos para la tenencia y uso de armas de fuego cuya expedición tendrá carácter restrictivo, especialmente cuando se trate de armas de defensa personal, en relación con las cuales la concesión de las licencias o permisos se limitará a supuestos de estricta necesidad”.

Esta licencia se encuentra regulada en los artículos 96 y ss. del Reglamento de armas aprobado por Real Decreto 137/1993 de 29 de enero modificado por Real decreto 540/1994 de 25 de marzo. 
se otorga a efectos cinegéticos. De ahí que la normativa exija la dedicación real del peticionario al ejercicio de la caza, circunstancia que puede acreditarse mediante exhibición de las correspondientes licencias de caza y tarjetas federativas en vigor ${ }^{27}$.

Como una garantía de seguridad, el otorgamiento de la licencia se supedita a que el beneficiario reúna las aptitudes psicofísicas adecuadas y acredite los conocimientos precisos en materia de conservación, mantenimiento y manejo de las armas, requiriéndose que de los antecedentes y conducta del solicitante no se desprenda una peligrosidad propia o ajena en el otorgamiento de la licencia ${ }^{28}$.

La vigencia de las licencias se halla condicionada al mantenimiento de los requisitos que fueron exigidos para su concesión y su pérdida justifica la revocación de la licencia, acto que, no tiene carácter sancionador y, por tanto, no se encuentra sometido a los requisitos de un procedimiento de esa naturaleza.

Como la licencia de armas no se otorgará a aquellas personas para las que la posesión y el uso de armas representen un riesgo propio y ajeno, los órganos encargados de la instrucción del procedimiento deben realizar un informe sobre la conducta y antecedentes del interesado, así como su dedicación real al ejercicio de la caza, lo cual nos conduce a la problemática que plantea la valoración administrativa de la conducta y antecedentes del interesado.

En todo caso la Administración habrá de motivar su decisión, especialmente cuando su resolución resulte denegatoria, y más aún cuando se produzca un cambio de criterio respecto al mantenido en ocasiones anteriores con la misma persona, siendo esta cuestión esencial para contrastar la legalidad de su actuación y facilitar el control judicial en su caso ${ }^{29}$.

\footnotetext{
${ }^{27}$ Artículo 97.2 del Reglamento de armas.

${ }^{28}$ Artículo 98 del Reglamento de armas.

${ }^{29}$ La sentencia del Tribunal Supremo de 19 de enero de 1996 anuló la denegación por parte de la Administración a un particular de la renovación de una licencia de armas, debido a la falta de motivación, toda vez que la licencia le había sido concedida en tres ocasiones anteriores, sin que el particular presentase antecedentes desfavorables, ni constara que hubieran variado fundamentalmente las circunstancias que fueron tomadas en cuenta para su otorgamiento.
} 


\section{EL DERECHO DE CAZA Y SU CONFIGURACIÓN}

La caza ha sido tradicionalmente objeto de interés del Derecho Privado, concretamente el Derecho civil ${ }^{30}$ ya venía a conocer los conflictos suscitados entre el derecho de propiedad y el derecho de caza, no obstante y dado que el principio de libertad de caza desaparece con el Imperio Romano, el derecho Público ha ido entendiendo con mayor intensidad de las cuestiones que surgen de la actividad cinegética.

Parte de la doctrina considera que el fundamento jurídico, de carácter dualista (público y privado) del derecho de caza, se deriva de los artículos 610 y 611 del Código civil. El primero, establece el principio de res nullius para las piezas objeto de caza, acogiéndose a la clásica definición romana ${ }^{31}$, el segundo señala que las leyes especiales regirán el Derecho de caza y pesca.

Al Derecho Público corresponde la conjugación del interés del cazador con los intereses colectivos, la determinación de las sanciones en caso de incumplimiento de las normas relativas a la caza, fijación de las tasas que gravan el ejercicio de la acción cinegética, etc.

Las personas que se hallen en posesión de las correspondientes autorizaciones administrativas tienen reconocida capacidad jurídica para cazar, que es diferente del derecho a cazar como aprovechamiento cinegético, en cuya titularidad se enfrentan los principios de libertad y propiedad. De este modo caben dos posibilidades para configurar el derecho de caza o bien se entiende que es éste un derecho derivado de la propiedad de los terrenos, sometido a límites o bien un derecho de los ciudadanos desvinculado de la propiedad.

\footnotetext{
${ }^{30}$ Código Civil Art. 610 "Se adquieren por la ocupación los bienes apropiables por su naturaleza que carecen de dueño, como los animales que son objeto de la caza y de la pesca, el tesoro oculto y las cosas muebles abandonadas".

611 "El derecho de caza y pesca se rige por leyes especiales".

Art. 1906 "El propietario de una heredad de caza responderá del daño causado por ésta en las fincas vecinas, cuando no haya hecho lo necesario para impedir su multiplicación o cuando haya dificultado la acción de los dueños de dichas fincas para perseguirlas."

Este último precepto constituye una prolongación del ámbito cinegético de la responsabilidad civil del poseedor de un animal por los daños que este ocasione y que se haya regulada en el artículo 1905.

${ }^{31}$ En un fragmento de Gayo incluido en el Digesto y que concibe el derecho de caza como un derecho natural perteneciente al hombre se dice que "quod enim nullius est, id ratione naturali ocupanti concedetur". El extenso derecho reconocido a los cazadores tenía como único límite, en relación con el de propiedad, la facultad del dueño del terreno para prohibir que en el se cazase.
} 
En la Ley de caza de 1970 se regula la titularidad del derecho de caza como resultado de diversas influencias desde el Derecho Romano, las regalías hasta la protección de la fauna silvestre, y no se pronuncia abiertamente sobre la titularidad del derecho a cazar reconociendo veladamente que el aprovechamiento cinegético es una facultad más del propietario. De hecho la titularidad dominical de los terrenos no permite el aprovechamiento exclusivo de la caza si el propietario no acota los terrenos así la Ley señala que en los cotos de un solo titular el derecho de caza corresponde a éste y a las personas por él autorizadas ${ }^{32}$ de manera que el acotamiento figura como una carga impuesta al propietario que desee reservarse el aprovechamiento cinegético. Pero por otra parte el propietario tiene un derecho al acotamiento para poder hacer efectiva su pretensión, acotamiento al que la Administración puede denegar la autorización, en cuyo caso la denegación ha de ser motivada correspondiendo a la Administración la carga de la prueba.

Por otra parte la Ley de 1970 también contempla la libertad de todos para cazar, manifestándose esta faceta en la regulación de terrenos de aprovechamiento cinegético común que abren la posibilidad de cazar a todos los ciudadanos. En este sentido puede decirse que la posibilidad de ejercer la caza al margen de la propiedad de algún modo subsidiaria del derecho del propietario a explotar cinegéticamente sus terrenos. Finalmente procede mencionar la constitución de los cotos sociales de caza, que tratan de facilitar el ejercicio de la caza en régimen de igualdad ${ }^{33}$.

\section{TERRENOS DE CAZA Y PIEZAS CINEGÉTICAS}

Nuestra legislación sólo permite la caza de aquellas especies declaradas como cazables, así la Ley 1/1970 dispone en su artículo 4.1 que "son piezas de caza los animales salvajes y los domésticos que pierdan esa condición que figuren en la relación que a estos efectos deberá incluirse en el reglamento para la aplicación de esta Ley", la Ley 4/1989 de 27 de marzo dispone en su artículo 33.1 que "la caza y la pesca en aguas continentales solo podrá realizarse sobre las especies que reglamentariamente se declaren como piezas de caza o pesca que en ningún caso podrá afectar a especies catalogadas."

\footnotetext{
${ }^{32}$ Artículo 16 de la Ley 1/1970 de caza.

${ }^{33}$ Ver artículo 18 de la Ley $1 / 1970$.
} 
El Real Decreto 439/1990 regula el Catálogo Nacional de Especies Amenazadas que con un criterio mínimo sólo cataloga como especies amenazadas las especies en peligro de extinción y las consideradas de interés especial sensibles y vulnerables ${ }^{34}$.

El Real Decreto 1095/1989 de 8 de septiembre por el que se declaran las especies objeto de caza y pesca y se establecen normas para su protección es la norma que determinaba las especies cazables, no obstante estas relaciones tendrán carácter supletorio de lo que establezcan las Comunidades Autónomas ya que el tribunal Constitucional declaró que la disposición establecida en el Real Decreto no tenía carácter básico ${ }^{35}$.

Respecto al ámbito espacial de la caza, la Ley de 1970 configura los terrenos de caza de manera expansiva dividiendo el territorio en terrenos de aprovechamiento cinegético común que no requieren intervención alguna (terrenos libres) y terrenos de régimen especial ${ }^{36}$. Los terrenos en los que la caza resulta prohibida ${ }^{37}$, se encuentran clasificados entre los sometidos a régimen especial, cuya calificación exige además la correspondiente intervención administrativa. Por ello salvo que por disposición expresa se declare el carácter no cinegético de un terreno o se le someta a un régimen especial, los terrenos tendrán la consideración de libres y en ellos estará permitido el ejercicio de la caza sin más limitaciones que las generales de la Ley y el Reglamento.

Por su parte la Ley 4/1989 de 27 de marzo prevé la concreta definición de los terrenos que tengan la condición de cinegéticos ${ }^{38}$.

\footnotetext{
34 Así las clasifica el artículo 29 de la Ley 4/1989 de 27 de marzo.

35 STC 102/1995 de 22 de junio.

36 Artículo 8.1 de la Ley 1/10970 de caza.

${ }^{37}$ Refugios de caza, zonas de seguridad y cercados.

38 Artículo 33.

2 "En todo caso, el ejercicio de la caza y de la pesca continentales regulará de modo que queden garantizados la conservación y el fomento de las especies autorizadas para este ejercicio, a cuyos efectos la Administración competente determinará los terrenos y las aguas donde puedan realizarse tales actividades, así como las fechas hábiles para cada especie”.

3 "Todo aprovechamiento cinegético y acuícola en terrenos acotados al efecto deberá hacerse por el titular del derecho, de forma ordenada y conforme al plan técnico justificativo de la cuantía y modalidades de las capturas a realizar, con el fin de proteger y fomentar la riqueza cinegética y acuícola”.
} 
Alguna doctrina se ha planteado si siendo la delimitación de los terrenos cinegéticos el único medio que permite asegurar un ejercicio ordenado y racional de la caza, en la línea marcada por la Constitución ${ }^{39}$ y si la propia Ley 4/1989 de 27 de marzo así lo estipula, habrá sido derogado el régimen de terrenos de aprovechamiento cinegético común establecido en la Ley de caza. La subsistencia de este régimen común pasa a juicio de dicha doctrina por que la Administración los delimite y adopte las medidas precisas para garantizar la práctica racional de la caza ${ }^{40}$.

Como terrenos de carácter especial examinaremos los cotos de caza, las reservas nacionales de caza, los refugios de caza y los terrenos cercados.

Se denomina coto de caza a la superficie continua de terreno susceptible de aprovechamiento cinegético que haya sido declarada y reconocida como tal por resolución administrativa. La continuidad de los terrenos susceptibles de convertirse en acotado no se considerará interrumpida por la existencia de ríos o arroyos, vías o caminos de uso público, ferrocarriles, canales o cualquier construcción de características similares ${ }^{41}$.

La declaración de coto de caza se realiza a petición de los titulares o patrocinadores interesados ${ }^{42}$. Si la constitución de un coto de caza lesionase otros intereses cinegéticos públicos o privados, la Administración podría denegar la autorización precisa para constituir el acotado, pudiendo el interesado recurrir la misma.

\footnotetext{
39 Constitución artículo " 45 1. Todos tienen el derecho a disfrutar de un medio ambiente adecuado para el desarrollo de la persona, así como el deber de conservarlo.

2. Los poderes públicos velarán por la utilización racional de todos los recursos naturales, con el fin de proteger y mejorar la calidad de la vida y defender y restaurar el medio ambiente, apoyándose en la indispensable solidaridad colectiva".

${ }^{40}$ LAGUNA J.C. op. cit. p. 207.

${ }^{41}$ Artículo 15 de la Ley 1/1970 de caza.

42 Una vez presentada la solicitud por los patrocinadores, la Administración inicia el correspondiente expediente y después de sometido a preceptiva información pública Resuelve lo que estime oportuno. Citando un supuesto concreto y reciente, la asociación de cazadores Peña Manteca presentó solicitud de declaración de coto regional a la Consejería de Medio Ambiente del Principado de Asturias la cual sometida a la correspondiente información pública resuelve mediante Resolución de 19 de enero de 2001 declarar la constitución del coto regional de caza de Belmonte núm. 065. BOPA núm 51 de 2 de marzo de 2001.
} 
En los terrenos acotados, la caza estará protegida y fomentada, quedando derogado el régimen común de libertad de caza ${ }^{43}$. Como contrapartida, los cotos se hallan sujetos a tributos locales ${ }^{44}$, además los cotos están sujetos al abono de una tasa en concepto de matrícula anual ${ }^{45}$ cuya cuantía se calculará en función del impuesto sobre gastos suntuarios.

Si un coto no cumple las finalidades de protección y fomento de la riqueza cinegética, la Administración puede anular la declaración que autorizó la constitución del acotado. Los cotos de caza en los que existan lugares de paso o parada de aves migratorias, el aprovechamiento de las mismas debe adaptarse a los planes que la Administración tenga establecidos para este tipo de aves.

Los cotos por otra parte deben ostentar en sus límites y a todos los aires las señales que la Administración determine.

La Ley de caza clasifica los cotos en privados locales y sociales ${ }^{46}$.

Los cotos privados son aquellos constituidos por los propietarios o titulares de los terrenos cinegéticos o los titulares de otros derechos reales o perso-

\footnotetext{
${ }^{43} \mathrm{El}$ acotamiento supone una reserva del aprovechamiento cinegético a sus titulares ya se trate de personas físicas o jurídicas. En los cotos privados de un solo titular el ejercicio del derecho de caza corresponderá a éste y a las personas por él autorizadas, en los integrados por asociación de titulares de terrenos colindantes el ejercicio del derecho de caza deberá ser determinado por sus miembros y obtener la aprobación administrativa. (Artículo 16 de la Ley de caza).

${ }^{44}$ Aunque el Impuesto municipal sobre gastos suntuarios aplicable a los cotos de caza y pesca fue sustituido por el Impuesto de actividades económicas, el Real Decreto-ley 4/1990 de 28 de septiembre dispuso que desde el 1 de enero de 1991, los Ayuntamientos podían continuar exigiendo el Impuesto municipal de gastos suntuarios exclusivamente en relación con el aprovechamiento de los cotos de caza y pesca, por ello permanecen vigentes sólo a los efectos de los cotos, las disposiciones por las que se rige este impuesto (art. 372. d) del Texto refundido de las Disposiciones legales vigentes en materia de régimen local y también las Ordenanzas municipales de este impuesto que los diversos ayuntamientos hayan aprobado.

45 Artículo 35 de la Ley de caza.

46 Artículo 15 de la Ley de caza. Las clasificaciones de la legislación autonómica son similares presentando algunas diferencia de carácter puramente nominal por ejemplo la Ley 2/1989 de 6 de junio de caza de Asturias establece en su artículo 12 que "Se denominan cotos regionales de caza a los que se constituyen sobre terrenos de aprovechamiento cinegético común o sobre los que, estando sometidos a un régimen cinegético especial debieran pasar a ser de aprovechamiento cinegético común".
} 
nales que lleven aparejado el disfrute del aprovechamiento de la caza. Para ello ha de tenerse en cuenta las siguientes condiciones:

- Los terrenos integrantes de esta clase de cotos podrán pertenecer a uno o varios propietarios que se hayan asociado voluntariamente con esa finalidad.

Cuando se trate de terrenos cuya propiedad corresponda pro indiviso a varios dueños, para constituir o integrarse en un acotado será preciso que concurra loa mayoría entendiendo como tal la que representa la mayor cantidad de los intereses que constituyan el objeto de la comunidad de dueños.

- Las superficies mínimas para constituir estos cotos serán:

Cuando pertenezcan a un solo titular, 250 hectáreas si el objeto principal del aprovechamiento cinegético es la caza menor.

Cuando pertenezcan a varios titulares $\mathrm{Si}$ el aprovechamiento es la caza menor la superficie mínima será de 500 hectáreas; si es la caza mayor 1000 hectáreas. No obstante en zonas donde solo sea posible la caza menor de pelo la Administración puede autorizar cotos privados de un solo propietario siempre que la superficie de la finca sea superior a 20 hectáreas. En circunstancias similares y tratándose de aves acuáticas la superficie mínima será de 100 hectáreas en casos excepcionales en que la superficie mínima exigida podrá ser menor.

- Los propietarios o titulares de cotos privados de caza pueden solicitar de la Administración competente, la agregación de fincas enclavadas, cuya superficie no exceda del 10 por 100 de la inicialmente acotada. También tienen esta posibilidad las parcelas cuyo perímetro linde en más de sus tres cuartas partes en el coto. Esto no será aplicable a las fincas de un solo titular cuya superficie sea superior a la mínima exigible para constituir un coto privado.

- En los cotos privados de un solo titular, el ejercicio del derecho de caza corresponde a éste y a las personas autorizadas por él.

- El ejercicio del derecho de caza en los cotos privados integrados por asociación de titulares de terrenos colindantes se halla sometido a la autorización de la Administración. Asimismo se hallan sometidas a autorización administrativa las características y el régimen orgánico de la asociación, la duración y las peculiaridades del arrendamiento o de la cesión del aprovechamiento ${ }^{47}$.

\footnotetext{
${ }^{47}$ Ver artículo 16 de la Ley 1/1970 de caza y 18 del Reglamento de caza de 1971.
} 
Son cotos locales de caza aquellos patrocinados por municipios y entidades locales menores en representación de los titulares del aprovechamiento cinegético voluntariamente adscritos al proyecto. Los terrenos aportados podrán ser propiedad de entidades públicas o de particulares, exigiéndose la misma extensión que en el caso de cotos $\operatorname{privados}^{48}$.

Por otra parte los cotos locales no pueden exceder en superficie, incluidos los enclaves ${ }^{49}$ del 75 por 100 de la superficie del territorio que constituya el término local de que se trate. Excepcionalmente la Administración podrá modificar estos límites. Asimismo cuando en un coto local existan terrenos enclavados no sometidos a aprovechamiento cinegético especial cuya superficie total no exceda de la cuarta parte de la del coto pueden solicitar a la Administración la inclusión de dichos terrenos en un coto con los mismos derechos y las mismas obligaciones. Además las entidades patrocinadoras pueden solicitar la constitución de cotos locales integrados por varios términos colindantes, siempre que la superficie aportada por cada entidad no exceda del 75 por 100 del total del territorio ${ }^{50}$.

La adjudicación del aprovechamiento cinegético en los cotos locales se realizará por el ayuntamiento o entidad local menor competente mediante pública subasta.

En los cotos locales, el ejercicio del derecho de caza recae en los adjudicatarios de los aprovechamientos o en quienes éstos autoricen. La duración del contrato de arrendamiento del aprovechamiento cinegético en estos cotos no puede ser menor de seis años si se trata de caza menor ni menor de nueve si se trata de caza mayor. Si en un terreno que forme parte de un coto local ya establecido, se pretende constituir un coto privado de caza, deberá notificar-

\footnotetext{
48 Artículo 17.2 de la Ley de caza.

${ }^{49}$ Las fincas agregadas al coto inicial artículo 17.3 de la Ley de caza.

${ }^{50}$ La generalización de los cotos locales de caza ha propiciado una notable reducción de los terrenos cinegéticos para las personas que no sean beneficiarias de su aprovechamiento, de manera especial los cazadores de zonas urbanas. Por ello la Ley limitó la extensión posible de estros cotos a un 75 por 100 de la superficie total del término municipal. No obstante en la práctica la intención de la Ley no siempre se cumple y en algunos casos los ayuntamientos crean cotos privados en lugar de cotos locales, respecto de los cuales no rige esta limitación, en otros casos se constituyen cotos privados en la superficie de terreno restante ( 25 por 100) del término muni-
} cipal. 
se a la entidad patrocinadora al menos con un año de antelación a la fecha de conclusión del arrendamiento o de la cesión del aprovechamiento. En caso contrario no podrá ejercitarse este derecho hasta que transcurra un nuevo turno de explotación ${ }^{51}$.

Se entiende por cotos sociales de caza aquellos cuyo establecimiento responde a la idea de facilitar el ejercicio de la caza en régimen de igualdad de oportunidades, a todos los españoles que lo deseen para quienes se encuentra reservada la caza en estos cotos.

Los cotos sociales pueden constituirse de oficio o a petición de las corporaciones locales y sociedades de cazadores. Su declaración titularidad, gestión y administración corresponde a la Administración autonómica que podrá recabar la colaboración de los municipios implicados y de las sociedades de cazadores. La distribución de los permisos para cazar en estos cotos se realizará de acuerdo con las normas que fije la Administración para cada coto ${ }^{52}$. La mitad de los permisos se otorgarán con carácter preferente a los cazadores residentes en la provincia o provincias en que los cotos se hallen localizados estando justificada esta medida a nuestro juicio en virtud de una especie de compensación a los cazadores regionales por la privación de terrenos cinegéticos libres que supone la propia constitución de los cotos en su entorno.

Los cotos sociales pueden constituirse sobre cualquier clase de terrenos susceptible de aprovechamiento cinegético, con independencia de su carácter público o privado (terrenos del Estado, terrenos sobre los que se haya contratado el servicio de coto social, terrenos ofrecidos por sus titulares para coto social, terrenos que no se hayan constituido como cotos locales cuando la Administración haya ejercitado el derecho de tanteo para adquisición como cotos sociales).

El ejercicio de la caza en los cotos sociales se prevé por la Administración dentro del marco del aseguramiento de la conservación de las especies cinegéticas, así como su fomento. En tales condiciones se aceptan las solicitudes para la práctica de la caza ${ }^{53}$.

\footnotetext{
51 Artículo 17 de la Ley de caza.

52 El artículo 20.8 del Reglamento de caza de 1971 fija un criterio que limita el precio de los permisos: los ingresos percibidos por este concepto no deben exceder del 80 por 100 del total de los gastos precisos para subvenir al establecimiento y adecuada protección, conservación y fomento de la riqueza cinegética del coto, sin que pueda computarse ningún gasto que corresponda al personal técnico o administrativo.

${ }^{53}$ Artículo 18 de la Ley de caza y 20 del Reglamento de caza.
} 
La modalidad de cotos deportivos que no se halla prevista en la Ley de caza de 1970, ha sido introducida por la normativa autonómica. Se denominan cotos deportivos los que sin ánimo de lucro, se encuentran afectados exclusivamente a una finalidad deportiva lo cual implica que la actividad o los resultados de estos terrenos en ningún caso podrán ser objeto de venta o comercialización, las normas que regulan esta modalidad establecen diversas condiciones para su constitución de las cuales podemos destacar la exigencia de una extensión mínima de superficie de terrenos. La gestión de estos cotos se lleva a cabo por sociedades deportivas de cazadores legalmente constituidas, municipios o federaciones de caza ${ }^{54}$.

Las zonas de caza controlada son espacios constituidos sobre terrenos cinegéticos de aprovechamiento común, en los que la protección, conservación, fomento y aprovechamiento de su riqueza cinegética se gestiona de acuerdo con los planes elaborados por la Administración. La constitución de estas zonas corresponde a la Administración autonómica que directamente o a través de sociedades de cazadores regulará y controlará el disfrute de la caza en estos terrenos, en los que el aprovechamiento cinegético se hará a partir de los permisos que con una preferencia a favor de los cazadores locales y provinciales establezca la Administración 55 .

Los permisos para el ejercicio de la caza se otorgarán en su mayor parte a los miembros de estas sociedades, reservando un porcentaje no inferior a la cuarta parte para cazadores no asociados.

Hay que señalar finalmente que si bien en algunas Comunidades Autónomas no se ha tenido en cuenta esta figura en otras las zonas de caza controlada tienen una gran relevancia en las que ocupan la mayor parte de los terrenos cinegéticos ${ }^{56}$.

54 Ver Artículo 19 de la Ley 8/1990 de 21 de diciembre de caza de Extremadura; artículo 19 de la Ley 12/1992 de 10 de diciembre de caza de Aragón y artículo 16 de la Ley 7/2003 de 12 de noviembre de caza y pesca fluvial de la Región de Murcia.

${ }^{55}$ La gestión de las zonas de caza controlada a través de sociedades de cazadores se realiza previa celebración del correspondiente contrato. Podrán formar parte de estas sociedades los titulares de derechos cinegéticos sobre terrenos sometidos a régimen de caza controlada, así como en su caso los titulares de terrenos incluidos en el coto local establecido sobre el municipio correspondiente. (Artículo 16 del Reglamento de caza de 1971).

${ }^{56}$ En la Comunidad Autónoma de Canarias, en el cabildo insular de Tenerife la práctica totalidad de la superficie cinegética útil modalidad de caza menor -con alguna excepción- se encuentra sometida al régimen de caza controlada. Plan Insular de Caza de Tenerife: 1994. 
Las reservas de caza son espacios, creados por la Ley, sobre comarcas $\mathrm{cu}$ yas especiales características de orden físico y biológico permitan la constitución de núcleos de excepcionales posibilidades cinegéticas ${ }^{57}$. En consecuencia el fin primordial de las reservas es la protección, conservación y fomento de determinadas especies tarea que llevará a cabo por la Administración estatal o autonómica según se trate de reservas nacionales y regionales de caza.

La constitución de una reserva de caza sólo tiene efectos cinegéticos, no afectando a las restantes actividades que puedan realizarse sobre los terrenos que se hallen comprendidos en ella ${ }^{58}$, tampoco afecta a las especies que puedan ser objeto de especial protección, Tanto las reservas nacionales como las regionales de caza responden a los mismos objetivos establecidos en la Ley de caza de 1970, regulándose como núcleos con excepcionales posibilidades cinegéticas, sometidos por ello a un régimen especial con el fin de promover y fomentar las especies de caza.

La adjudicación de los permisos de caza previamente solicitados en las reservas de caza se adjudicará mediante sorteo público celebrado por la Administración.

Durante la cacería en las reservas el cazador deberá ir acompañado por un guarda o guía, que ostentará la representación de la Administración y cuyas decisiones han de ser respetadas en cuanto se refiera a la acción de caza. Este guía indicará al cazador las piezas sobre las que puede disparar, pudiendo también suspender la cacería ${ }^{59}$.

\footnotetext{
${ }^{57}$ Artículo 12.1 de la Ley de caza.

${ }^{58}$ Ley $37 / 1966$ de 31 de octubre.
}

${ }^{59}$ La actividad de caza en las reservas se encuentra regulada en cuanto a la realización de los disparos con sangre, sin sangre y sobre urogallo. Al término de las cacerías en que se hayan efectuado disparos con sangre, el cazador deberá liquidar las cuotas complementarias de su permiso, procediendo el guardo o funcionaria a evaluar los trofeos basándose en las normas establecidas por la Junta Nacional de Homologación de Trofeos de Caza estableciéndose además una serie de puntuaciones fijas por especie. Determinada la puntuación que corresponda, se calculará el importe de la cuota complementaria por la aplicación de los baremos correspondientes, debiendo quedar en poder de la reserva aquellos trofeos o animales que por su interés científico así lo decida la dirección técnica y aquellos que obtengan puntuaciones superiores a las establecidas. También se establecen normas para liquidar normas heridas y no cobradas y normas para casos de disconformidad.

Ver: Ley 371/1966 de 31 de mayo creación de Reservas nacionales de caza; Ley 2/1973 de 17 de marzo creación de 13 Reservas; Orden de 17 de diciembre de 1973 regula ejercicio de la caza en Reservas y cotos nacionales; Decreto de 2612/1974 de 9 de agosto de Regulación de las Re- 
Como terrenos no cinegéticos en los que se encuentra excluido el derecho de caza podemos mencionar los refugios de caza, las zonas de seguridad y los terrenos cercados.

Son refugios de caza los espacios creados para asegurar la conservación de determinadas especies de fauna cinegética, siempre que razones biológicas, científicas o educativas así lo aconsejen. Su establecimiento puede promoverse, por entidades privadas con fines culturales o científicos o por entidades públicas. Estos refugios pueden denominarse estaciones biológicas o zoológicas, de conformidad con las finalidades perseguidas y serán administrados por las entidades que hayan promovido su establecimiento, ateniéndose a las disposiciones reglamentarias fijadas por la Administración. En cada caso concreto. Cualquiera que sea la condición de los refugios la caza estará prohibida de modo permanente salvo que por razones de interés biológico, técnico o científico se autorice la caza.

Las zonas de seguridad son aquellos espacios en los que deben adoptarse medidas precautorias especiales frente a la actividad cinegética, encaminadas a garantizar la adecuada protección de las personas y sus bienes ${ }^{60}$. En las zonas de seguridad se encuentra prohibido o al menos condicionado el uso de armas de fuego, extendiéndose estas limitaciones a las zonas en que pueda resultar perjudicado el ganado o su normal pastoreo.

Finalmente la Ley de caza prohíbe la actividad cinegética en los terrenos cercados, entendiéndose por tales aquellos que se encuentran materialmente rodeados por muros, cercas vallas, setos o cualquier obra o dispositivo construido con el fin de impedir o prohibir el acceso de las personas o animales ajenos o de evitar la salida de los propios. No tendrán esta consideración los terrenos rurales cercados en los que se pueda penetrar a través de accesos practicables, salvo que el propietario -mediante señales- haya hecho patente la prohibición de entrada en ellos ${ }^{61}$.

servas nacionales de caza; Orden de 29 de noviembre de 1977. Reglamento de caza selectiva en Reservas y cotos nacionales; real decreto 891/1979 de 26 de enero Modifica en Decreto 2612/1974 de 9 de agosto; Real decreto 1105/1982 de 14 de mayo sobre actuación del Instituto de Conservación de la Naturaleza en zonas de influencia socioeconómica.

${ }^{60}$ En general tienen esta consideración las vías y caminos de uso público, vías pecuarias, vías férreas, las aguas públicas -incluidos cauces y sus márgenes- los canales navegables, los núcleos urbanos y rurales, las zonas habitadas y sus proximidades, las villas, jardines, parques destinados al uso público y los recintos deportivos, así como otros lugares que por sus características se hagan acreedores de esta calificación (artículo 13.2 de la Ley de caza y 14 del Reglamento de caza).

${ }^{61}$ Artículo 19 de la Ley de caza. 


\section{RÉGIMEN DE PROPIEDAD DE LAS PIEZAS}

La fauna silvestre objeto de caza no se encuentra hoy en día en España afectada al uso público o servicio público ni tampoco al fomento de la riqueza nacional y el régimen de propiedad de las piezas de caza es una cuestión de Derecho Privado que se regula por el Derecho común.

De conformidad con lo establecido en el Código Civil las piezas de caza se consideran propiedad del que las caza, que las adquiere por ocupación. Las piezas de caza se entiende que están ocupadas desde el momento en que el cazador les da muerte o bien se procede a su captura.

La Ley de caza de 1970 dispone en su artículo 22 que la ocupación se entenderá producida desde la muerte o captura de la pieza. Por ello siempre que la práctica cinegética se ajuste a las prescripciones legales la muerte o captura confiere al cazador la propiedad sobre las piezas de caza.

La Ley posibilita asimismo a que el cazador cobre la pieza en terreno donde le esté permitido cazar, aunque entre en propiedad ajena, asimismo la Ley reconoce al cazador el derecho de persecución de la pieza, entendiéndose que una pieza es perseguida cuando el cazador que la levantó vaya en su seguimiento y tenga razonable posibilidad de cobrarla, este derecho supone una preferencia exclusiva derivada del ejercicio de la caza. Cuando se dude, de la propiedad de las piezas de caza, se aplicará la costumbre del lugar. Cuando no exista costumbre al efecto, la propiedad será atribuida al cazador que las hubiese dado muerte, en caso de caza menor, o al autor de la primera sangre, en caso de caza mayor ${ }^{62}$. Cuando se trate de aves en vuelo la propiedad de las mismas será del cazador que las hubiera abatido. La propiedad de las piezas también puede ser objeto de acuerdo por parte de los cazadores.

Hay supuestos en que el cazador no es propietario de la pieza cobrada como en caso de caza en cotos nacionales o reservas nacionales de caza. Si existe disconformidad entre el cazador y el agente de guardería encargado de evaluar el importe que deba abonar el cazador por la obtención del ejemplar, el cazador una vez liquidado el permiso de caza, solo tendrá derecho al trofeo. En el supuesto de que el cazador hubiera obtenido trofeos excepcionales, la Administración se reserva el derecho de retener los trofeos durante el tiempo preciso para obtener un duplicado de los mismos. Quedan en propiedad de la

\footnotetext{
62 Artículo 22 de la Ley de caza.
} 
reserva o del coto nacional aquellos trofeos o animales que, por su interés particular, la Administración considerase que deberían quedar en poder de la reserva, esta decisión ha de fundamentarse en una de las siguientes circunstancias: ser de interés específico o ser un trofeo de excepcional puntuación.

\section{ASOCIACIONES Y FEDERACIONES DE CAZA}

La caza deportiva actividad libre y voluntaria presenta el aspecto de la práctica del ciudadano como actividad espontánea y lúdica y la actividad deportiva organizada a través de estructuras asociativas. Dentro de este último aspecto la actividad deportiva de la caza presenta un primer nivel de asociación de particulares compuesto por las sociedades, asociaciones, clubes, o agrupaciones dedicadas a la práctica del deporte de la caza y un segundo nivel representado por las Federaciones de caza como formas asociativas de segundo grado.

Con respecto a las asociaciones del primer nivel hemos de señalar que su regulación entra de lleno la normativa reguladora de las asociaciones o clubes deportivos entendiéndose por tales las asociaciones privadas integradas por personas físicas o jurídicas que tengan por objeto la promoción de una o varias modalidades deportivas, la práctica de las mismas por sus asociados, así como la participación en actividades y competiciones deportivas ${ }^{63}$.

Para la constitución de una asociación o club de cazadores será suficiente que sus promotores o fundadores, siempre personas físicas, suscriban un documento privado en que figure, como mínimo el nombre de los fundadores o promotores y del delegado responsable, la voluntad de constituir la asociación, finalidad y nombre de la mismas, un domicilio a efectos de notificaciones y relaciones con terceros y la constancia expresa del sometimiento a las normas deportivas y en su caso a las que rigen las de la Federación española de caza. Estos clubes o asociaciones podrán establecer normas de funcionamiento de carácter interno siempre de conformidad con principios democráticos y representativos ${ }^{64}$.

\footnotetext{
63 Ver artículo 13 de la Ley 10/1990 de 15 de octubre, del Deporte, modificada por la Ley $50 / 1988$.

${ }^{64}$ Artículo 16 de la Ley del Deporte.
} 
Respecto a las federaciones hay que señalar que son entidades privadas, con personalidad jurídica propia y un ámbito de actuación determinado que si bien tienen una naturaleza jurídico-privada se les atribuyen al tiempo funciones de carácter público administrativo, sustentándose en esta dimensión las diferentes normas de tutela y control que la Administración puede ejercer sobre ellas.

Las Federaciones deportivas españolas tienen un ámbito de actuación que se extiende a todo el territorio del Estado en el desarrollo de sus competencias y están integradas por Federaciones de ámbito autonómico, asociaciones o clubes deportivos y otros colectivos interesados. Su estructura interna estará regulada a través de sus Estatutos ${ }^{65}$.

La Federación Española de Caza es la entidad que agrupa a los deportistas, entidades y otros dedicados a la práctica del deporte de la caza y actividades conexas asumiendo la dirección técnico-deportiva de las actividades cinegéticas en sus aspectos deportivos ${ }^{66}$. Se trata de una entidad privada sin ánimo de lucro, con personalidad jurídica propia y plena capacidad de obrar para el cumplimiento de sus fines y con patrimonio propio independiente de sus asociados.

\footnotetext{
65 Artículos 30 y 31 de la Ley del Deporte.

Sobre Federaciones deportivas ver además las siguientes normas:

Real Decreto 1835/1991 sobre Federaciones Deportivas españolas, modificado por Real Decreto 1252/1999 16 de julio.

Real Decreto 177/1981 sobre Clubes y Federaciones Deportivas modificado por Real Decreto
} 2588/1985 de 20 de noviembre.

\footnotetext{
${ }^{66}$ Los Estatutos de la Federación Española de Caza fueron aprobados por Resolución de 23 de mayo de 1994 de la SECRETARIA DE ESTADO-PRESIDENCIA DEL CONSEJO SUPERIOR DE DEPORTES por la que se dispone la publicación de los Estatutos de la Federación Española de Caza. Estos estatutos han sido posteriormente modificados por Resolución de la misma Secretaría de Estado de 11 de abril de 1996 y por Resolución del CONSEJO SUPERIOR DE DEPORTES de 16 de octubre de 1996.

El artículo 1 de los Estatutos establece que La Federación Española de caza "es la entidad del derecho privado que agrupa con carácter obligatorio a los deportistas profesionales o aficionados, jueces y árbitros, a las sociedades o asociaciones, clubes o agrupaciones dedicados a la práctica del deporte de la caza o actividades que con ella se relacionan, asumiendo de acuerdo con las disposiciones legales vigentes, la dirección técnico-deportiva de las actividades cinegéticas en sus aspectos deportivos en general de caza mayor y menor, caza con arco, competitivas de caza menor con perro, caza San Huberto, perros de muestra, perros de caza, pichón a brazo, cetrería, pájaros de canto, recorridos de caza, tiro a caza lanzada, caza fotográfica y vídeo y otras modalidades de práctica cinegética existentes o que se puedan crear, conforme a lo dispuesto en la Ley 10/1990, del Deporte, el presente Estatuto y Reglamento de la FEC y disposiciones de los Organismos Internacionales correspondientes".
} 
El ámbito de su jurisdicción se extiende a todo el territorio español para el desarrollo de sus competencias.

La Federación Española de Caza al igual que otras Federaciones deportivas se halla integrada en el Consejo Superior de Deportes, en el Comité Olímpico español y es el único organismo deportivo legitimado para representar al Estado español en el ámbito internacional en materia de caza deportiva. Actualmente está integrada en la Federación de Asociaciones de la Comunidad Europea (FACE) y en la Federación internacional de Tiro con armas deportivas de caza así como afiliada al Comité organizador del campeonato del mundo de caza.

La FEC bajo la coordinación del Consejo Superior de Deportes ejerce las siguientes funciones: Califica y organiza, las actividades y competiciones deportivas oficiales de ámbito estatal, actúa en coordinación con las federaciones de ámbito autonómico para la promoción general de su modalidad deportiva en el territorio nacional, diseña los planes de preparación de deportistas de alto nivel, colabora con la Administración en la formación de técnicos deportivos, organiza competiciones oficiales ejerce potestad disciplinaria deportiva, ejerce el control de subvenciones asignadas a las asociaciones y entidades deportivas y ejecuta las resoluciones del Comité Español de disciplina deportiva, otorgar títulos de aptitud respecto a pruebas deportivas, etc.

La Federación Española de Caza está integrada por las federaciones deportivas de ámbito autonómico, clubes y asociaciones deportivas, deportistas, jueces y árbitros y su estructura orgánica está compuesta como órganos de gobierno por la Asamblea General, la Comisión Delegada de la Asamblea y el Presidente como órganos complementarios establecen los Estatutos, la Junta Directiva, el Comité Ejecutivo, el Comité de Competiciones, el Secretario General y el Gerente los cuales asisten al Presidente y la Comisión Delegado que asiste a la Asamblea.

Los Estatutos establecen las funciones de todos estos órganos y la organización territorial de la Federación.

La licencia federativa es el instrumento básico para adquirir la calidad de miembro de la Federación Española de caza la solicitud y obtención comporta para su poseedor la asunción y el acatamiento expreso de los Estatutos. Para la participación en competiciones deportivas será preciso hallarse en posesión de la correspondiente licencia expedida por la Federación, las licencias expedidas por las federaciones de ámbito autonómico también habilitarán pa- 
ra participar en actividades o competiciones de ámbito estatal o internacional, sean o no oficiales que se celebren dentro del territorio español.

Finalmente los Estatutos regulan entre otras cuestiones, las relativas los procedimientos de elección el régimen financiero y patrimonial, el régimen disciplinario federativo y la modificación de Estatutos.

\section{RESPONSABILIDAD POR DAÑOS}

Este aspecto es el que más se acomoda al Derecho privado ya que junto al derecho a ejercer esta actividad, la Ley prevé el resarcimiento de daños y perjuicios al propietario de las fincas o terrenos que hubieran sufrido daños como consecuencia de la caza. Al tratarse de una materia de derecho privado, la Ley remite al derecho civil ordinario en muchas ocasiones, limitándose a señalar el responsable y los supuestos que hay que tener en cuenta para pedir responsabilidades en caso de daños.

Desde luego el ejercicio de la caza puede ser causa de daños y por lo tanto de responsabilidad. Los daños pueden tener su origen en tres ámbitos diferentes, las especies protegidas, el aprovechamiento cinegético de los terrenos y la práctica de la caza.

Respecto a los daños que produzcan las especies protegidas, el ordenamiento atribuye a los poderes públicos la efectiva protección de la fauna, que puede estar en el origen de la producción de daños a terceros. En este caso entrará en juego el sistema de responsabilidad patrimonial de la Administración establecido en la constitución que se sancionará conforme a la normativa general de Derecho Administrativo ${ }^{67}$. Este sistema de responsabilidad se debe a que sobre estas especies se ha producido una publificación que hace a la Administración responsable por los daños que produzcan, por otra parte se trata de animales sin dueños -res nullius- se acentúa la responsabilidad admi-

\footnotetext{
${ }^{67}$ Constitución española artículo 106.2 "Los particulares, en los términos establecidos por la Ley, tendrán derecho a ser indemnizados por toda lesión que sufran en cualquiera de sus bienes y derechos, salvo en los casos de fuerza mayor, siempre que la lesión sea consecuencia del funcionamiento de los servicios públicos".

Artículos 139 a 146 de la Ley 30/1992 de 26 de noviembre de Régimen Jurídico de las Administraciones Públicas y del Procedimiento Administrativo Común y 121 y 122 de la Ley de expropiación forzosa de 16 de diciembre de 1954.

El Reglamento 429/1993 de 26 de marzo aprobó el Reglamento de los procedimientos de las Administraciones Públicas en materia de responsabilidad patrimonial.
} 
nistrativa que se deriva de la decisión pública que impide cazarlas, perturbarlas o combatirlas. Esta responsabilidad de la Administración establecida con carácter general se encuentra en muchos casos ratificada por la propia legislación sobre caza que la hace extensiva a las especies de fauna silvestre no cinegética ${ }^{68}$.

El aprovechamiento cinegético de los terrenos es potencial causa de producción de daños de manera especial para los cultivos agrícolas o forestales próximos, así la Ley de 30 de marzo de 1954 sobre daños producidos por la caza se dictó precisamente para ello ${ }^{69}$ elaborándose para regular los medios de protección frente a los daños ocasionados a los cultivos por las piezas de caza.

La Ley de 1970 regula la responsabilidad de los daños producidos por las piezas de caza, permitiendo la defensa activa de los perjudicados frente a dichos daños. Así la Ley de caza ${ }^{70}$ prevé que la Administración pueda autorizar a instancia de parte a los dueños de las fincas que hayan visto perjudicadas sus

${ }^{68}$ La Ley 2/1989 de 6 de junio de caza de Asturias dispone que "Serán indemnizados por la Administración del Principado de Asturias, previa instrucción del oportuno expediente y valoración de los daños efectivamente producidos:

...b) los daños ocasionados por especies de la fauna silvestre no susceptibles de aprovechamiento cinegético, cualquiera que sea su procedencia".

La Ley 8/1990 de 21 de diciembre de caza de Extremadura dispone en su artículo 74.1 que "Serán indemnizados por la Administración regional previa instrucción del oportuno expediente y las valoraciones a que hubiere lugar:

b) los daños ocasionados por especies de la fauna silvestre no cinegética, cualquiera que sea su procedencia”.

El artículo 72.1a) de la Ley de caza de Aragón "Serán indemnizados por la Dirección General, previa instrucción del oportuno expediente y valoración de los daños producidos:

a)Los daños ocasionados por las especies cinegéticas procedentes de los terrenos no cinegéticos.

b) Los daños ocasionados por especies de la fauna silvestre no susceptibles de aprovechamiento cinegético, cualquiera que sea su procedencia".

Por otra parte la Ley 7/1995 de Fauna silvestre, caza y pesca fluvial de Murcia dispone la adopción por parte de las Comunidades Autónomas de las medidas necesarias para prevenir los posibles daños que puedan ocasionar las especies amenazadas. La oposición por parte del afectado dará lugar a la pérdida del derecho de indemnización que en otro caso le correspondería, no resultando indemnizables los daños causados por especies que hayan sido declaradas por el órgano autonómico competente como plaga, o respecto de las cuales se hubiera autorizado con anterioridad su captura controlada. (artículos $4,30.4$ y 30.5).

${ }^{69}$ Esta Ley junto con la Orden Ministerial de desarrollo fue expresamente derogada por la Ley de caza de 1970.

${ }^{70}$ Artículo 33.4 de la Ley 1/1970 de caza y 35.5 del Reglamento de caza de 1971. 
producciones agrícolas, ganaderas o forestales por causa de la caza, pueda llevar a cabo en sus terrenos las medidas de carácter cinegético que sean precisas para proteger sus cultivos, así la Orden Ministerial de 18 de marzo de 1972 sobre batidas para proteger los cultivos agrícolas.

Además la Ley establece un régimen de responsabilidad por daños producidos por las piezas de caza, diferentes para clase de terreno, así en terrenos de aprovechamiento cinegético especial se imponen ventajas cinegéticas a sus titulares o limitaciones de caza en beneficio de la colectividad por ello se explica que la Administración se encuentre obligada a responder del perjuicio que en fincas próximas ocasionen las piezas de caza procedentes de estos terrenos $^{71}$.

En el caso de cotos de caza, la Ley responsabiliza a los titulares de los derechos de aprovechamiento cinegético y subsidiariamente a los titulares del terreno, de los daños producidos por las piezas de caza procedentes de los terrenos acotados ${ }^{72}$. La exacción de estas responsabilidades -dice el artículo 33.2 de la Ley- se ajustará a las prescripciones de la Ley ordinaria matizando que en supuesto de cotos constituidos por asociación se establece la responsabilidad solidaria que el Reglamento en su artículo 35 I a) limita a los que aportaron voluntariamente sus fincas al coto.

La normativa autonómica si bien sanciona la responsabilidad del titular del aprovechamiento cinegético no menciona la del titular del terreno ${ }^{73}$.

Respecto a los daños producidos por las especies de caza procedentes de otros terrenos cinegéticos especiales como reservas nacionales, parques nacionales y terrenos de caza controlada si bien la Ley de caza de 1970 prevé la responsabilidad de los titulares de los aprovechamientos y subsidiariamente de la Administración, el Reglamento matiza que cuando se trate de daños de

\footnotetext{
${ }^{71}$ Se trata de un supuesto de responsabilidad objetiva establecido ex lege. Frente al régimen establecido con carácter general en el artículo 1906 del Código Civil la Ley de caza constituye un específico régimen de responsabilidad objetiva que como ha declarado la jurisprudencia del tribunal Supremo, se encuentra "al margen de la acción u omisión directas que comportan la mediación de culpa que es preciso probar”. STS de 27 de mayo de 1985.

72 Artículo 33.1 de la Ley 1/1970 de caza.

73 Artículo 38.2 de la Ley de Caza de Asturias, 74.2 de la Ley de caza de Extremadura y 72.2 de la Ley de caza de Aragón.
} 
caza procedente de estos terrenos será de aplicación lo previsto en la Ley o disposición especial que autorice su creación y, en su defecto, lo dispuesto en la legislación civil ordinaria" $" 4$.

La legislación autonómica prevé la indemnización por las respectivas Administraciones, así la Ley de caza de Extremadura dispone la indemnización previa instrucción de expediente y valoración previa de "los daños ocasionados por especies cinegéticas de los terrenos sometidos a Régimen cinegético especial, que no sean objeto de concesión administrativa para su aprovechamiento privado o deportivo" la Jurisprudencia ha confirmado la responsabilidad patrimonial de la Comunidad Autónoma por daños y perjuicios sufridos por el recurrente en los cultivos arbolados, pastos por los animales de una reserva de caza, al no hallarse correctamente deslindada y vallada ${ }^{76}$.

Respecto a la responsabilidad por daños de la caza procedente de terrenos de aprovechamiento común la Ley de caza no la menciona y el Reglamento remite a lo dispuesto por el Derecho civil (Código civil artículo 1906) sobre responsabilidad ${ }^{77}$. Este supuesto de responsabilidad civil extracontractual conlleva el deber de indemnizar fundado "en la inexistencia de pasividad o actitud negativa por parte del dueño del predio o, en su caso, del titular del derecho de caza, que comporta negligencia e incumplimiento de una carga de vecindad" $"$, por otra parte la jurisprudencia declaró, para que este precepto resulte de aplicación, que la caza debe ser la principal explotación del inmueble ${ }^{79}$. A este respecto señala la doctrina que parece razonable que la responsabilidad del pro-

\footnotetext{
${ }^{74}$ Artículos 33.3 de la Ley de caza de 1970 y 35.2 del Reglamento de 1971 . Hay que señalar que en la mayoría de estos supuestos se dará responsabilidad directa de la Administración.

75 Artículo 74.1.a) de la Ley de caza de Extremadura, artículo 38.1 a9 de la Ley de caza de Asturias; artículo 72.1c) de la Ley de caza de Aragón y artículo 30.1 de la Ley de Fauna silvestre, caza y pesca fluvial de Murcia.

${ }^{76}$ STS de 4 de julio de 1995.

77 Artículo 35.3.

El artículo 1906 del Código Civil dispone que "El propietario de una heredad de caza responderá del daño causado por ésta en las fincas vecinas, cuando no haya hecho lo necesario para impedir su multiplicación o cuando haya dificultado la acción de los dueños de dichas fincas para perseguirla".

${ }^{78}$ STS de 14 de julio de 1982.

${ }^{79}$ STS de 21 de febrero de 1911.
} 
pietario surja en el caso de que éste haya dificultado la acción de los dueños de las fincas próximas, o de la propia Administración, para impedir la multiplicación de las piezas de caza o la producción de daños. En otros casos la responsabilidad del propietario debe quedar reservada a supuestos en que éste se comporte de manera negligente ${ }^{80}$, en otros supuestos la responsabilidad habría de recaer sobre quienes se benefician de la caza, que en el caso de terrenos de aprovechamiento común, es la propia colectividad en este sentido la normativa autonómica atribuye la responsabilidad de estos daños a la Administración autonómica así la Ley de caza de Asturias dispone que serán indemnizados por la Administración del Principado de Asturias previa instrucción de expediente y valoración de los daños producidos a) los daños ocasionados por las especies cinegéticas procedentes de los terrenos cinegéticos de aprovechamiento común y de los cotos regionales de caza que no sean objeto de concesión, en Navarra se prevé asimismo la responsabilidad administrativa por daños causados a los cultivos por las especies cinegéticas que procedan de terrenos cuya titularidad corresponda a la administración de la Comunidad Autónoma -cuando no formen parte de cotos de caza-y por las especies cinegéticas procedentes de terrenos no $\operatorname{acotados}^{81}$.

En materia de caza la Administración tiene muchas competencias de cuyo ejercicio pueden derivarse daños para terceros de los cuales la Administración resultará responsable. Entre las competencias de la Administración se encuentra la determinación de las especies cinegéticas lo que hace que deba asumir en consecuencia los daños ocasionados por las especies de la fauna silvestre no susceptibles de aprovechamiento cinegético, cualquiera que sea su procedencia, al determinarlos terrenos donde se puede cazar, también resulta obligada a asumir los daños ocasionados por las especies cinegéticas procedentes de los terrenos no cinegéticos.

Por otra parte la Administración es responsable de los daños ocasionados por el deficiente ejercicio de sus competencias, así un retraso en la resolución de un expediente o una denegación injustificada de las medidas solicitadas pueden ser fuente de responsabilidad administrativa. Por lo tanto el titular del aprovechamiento cinegético se encuentra libre de responsabilidad en caso de que por cumplimiento de mandatos de la Administración resulten terceros perjudicados.

\footnotetext{
${ }^{80}$ Por ejemplo desatendiendo instrucciones o mandatos de la Administración.

81 Artículo 1 de la Orden Foral 108/1996 de 1 de marzo, de la Comunidad Autónoma de Navarra.
} 


\section{SEGURO OBLIGATORIO DEL CAZADOR}

Todo cazador se encuentra obligado a indemnizar los daños que cause con motivo del ejercicio de la caza, excepto cuando el hecho fuera debido sólo a culpa o negligencia del perjudicado o a fuerza mayor, no considerándose como tal, los defectos, roturas o fallos de las armas de caza y sus mecanismos o de las municiones ${ }^{82}$. Cuando no conste el autor del daño ocasionado a personas, en la caza con armas, responderán solidariamente todos los miembros de la partida de caza.

Como consecuencia de la situación de riesgo que el cazador produce con la práctica de la caza con armas, la ley impone la obligación de contratar un seguro obligatorio que cubra los daños causados a las personas ${ }^{83}$.

El seguro que cubre esta responsabilidad es por tanto un seguro de responsabilidad civil y así se encuentra clasificado por las normas técnicas de clasificación de los diferentes ramos de seguro ${ }^{84}$.

El seguro de responsabilidad civil del cazador, tiene gran conexión con el de circulación, rigiéndose prácticamente por módulos similares ${ }^{85}$. Su regulación se establece por el Reglamento del seguro obligatorio de responsabilidad civil del

${ }^{82}$ Artículo 33.5 de la Ley 1/1970 de caza y 35.6 del Reglamento de caza.

${ }^{83}$ Artículo 52 de la Ley y del Reglamento de caza.

${ }^{84}$ La Resolución de 12 de noviembre de 1982 de la Dirección General de Seguros por la que se da cumplimiento a la Orden de 29 de julio de 1982 que clasifica los ramos de seguros establece dentro del ramo 13 de Responsabilidad Civil General y del apartado b) otros riesgos el seguro obligatorio del cazador.

${ }^{85}$ La regulación de tarifas e incrementos suele ser común en ambos casos, lo mismo sucede en cuanto a las compañías aseguradoras.

El Reglamento del Consorcio de compensación de seguros establece en su artículo 10 "Funciones en relación con el Seguro Obligatorio de Responsabilidad Civil del Cazador.- El Consorcio de Compensación de seguros otorgará la cobertura y ejercerá las funciones atribuidas al extinguido Fondo Nacional de Garantía de Riesgos de la Circulación por el Reglamento del seguro Obligatorio de Responsabilidad Civil del Cazador". (Real Decreto 731/1987 de 15 de mayo).

Hay que señalar que por Real Decreto 2878/1981 de 13 de noviembre el Consejo de Compensación de Seguros había asumido las funciones y recursos del organismos autónomo Fondo Nacional de Garantía de Riesgos de la Circulación. 
cazador de suscripción obligatoria aprobado por Real Decreto 63/1994 de 21 de enero $^{86}$.

En el preámbulo del Real Decreto de aprobación se manifiesta la proximidad existente entre este seguro y el derivado del uso y circulación de vehículos de motor por tener idéntica naturaleza que debido al cambio de la realidad en que se desenvuelve la caza se hacía preciso acomodar este seguro al conjunto de disposiciones que se han promulgado en los últimos años sobre materia de seguros y de caza ${ }^{87}$ y finalmente fijar un nivel adecuado de protección a las víctimas de los accidentes ocasionados con motivo del ejercicio de la caza.

El seguro obligatorio de responsabilidad civil del cazador cubre en todo el territorio español la obligación del cazador con armas de indemnizar los daños corporales causados con éstas a las personas ${ }^{88}$. Se incluyen asimismo los daños personales producidos en caso de disparo involuntario de armas, entendiéndose que se ha producido en el ejercicio de la caza y los daños ocasionados en tiempo de descanso dentro de los límites del terreno de caza en tanto se esté practicando el ejercicio de la misma y los supuestos de responsabilidad concurrente del asegurado.

Quedan excluidos del ámbito de cobertura los supuestos en que el cazador no estuviera obligado a indemnizar porque el hecho fuera debido únicamente a culpa o negligencia del perjudicado o a la fuerza mayor en cuyo ámbito no se consideran incluidos los fallos, roturas de las armas de caza y sus mecanismos o de las municiones ${ }^{89}$.

\footnotetext{
${ }^{86}$ Este Real Decreto derogó expresamente la Orden Ministerial de 20 de julio de 1971 que había establecido el reglamento provisional del seguro obligatorio de responsabilidad civil del caz<ador y la Orden de 14 de octubre de 1983 (Economía y Hacienda) sobre prestaciones y tarifas en el seguro obligatorio del cazador normas que habían venido regulando este seguro..

${ }^{87}$ Ley 50/1980 de 8 de octubre, de Contrato de seguro; Ley 33/1984 de 2 de agosto sobre ordenación de seguro privado; Ley 21/1990 de 19 de diciembre para transponer la Directiva comunitaria 88/357/CEE sobre libertad de servicios en seguros distintos al de vida y de actualización de la legislación de seguros privados; la Ley 13/1992 de 1 de julio de Recursos propios y supervisión en base consolidada de las entidades financieras; Ley 4/1989 de 27 de marzo de Conservación de los espacios naturales y de la flora y fauna silvestre.

${ }^{88}$ El límite cuantitativo de indemnización de los daños corporales es de quince millones de pesetas por víctima. Artículo 3 del Reglamento del seguro obligatorio de responsabilidad civil del cazador, de suscripción obligatoria.

${ }^{89}$ Artículo 2 del Reglamento del seguro de responsabilidad civil del cazador de suscripción obligatoria.
} 
Por el seguro de responsabilidad civil la compañía aseguradora se obliga, dentro de los límites establecidos en la Ley y en el contrato, a cubrir el riesgo de la obligación que surja para el asegurado de indemnizar a un tercero perjudicado los daños causados por un hecho previsto en el contrato de cuyas consecuencias será responsable el propio asegurado ${ }^{90}$.

En el contrato de seguro obligatorio sobre responsabilidad civil del cazador intervienen el cazador asegurado a cuyo nombre se realiza el seguro, el asegurador que es la persona jurídica o compañía que cubre los riesgos y el tomador del seguro que es la persona que realiza el pago del seguro que puede coincidir con el cazador asegurado o ser un tercero.

El cazador puede, de manera voluntaria, extender la cobertura del seguro suscribiendo pólizas adicionales o incluyendo en la misma póliza otras coberturas del seguro que permite el artículo 4 del Reglamento ${ }^{91}$, en todo caso quedan excluidos de la cobertura los daños originados en los supuestos debidos a culpa o negligencia del perjudicado o fuerza mayor.

${ }^{90}$ Artículo 73 de la Ley 50/1980 de 8 de octubre de contrato de seguro.

91 Con carácter general las pólizas de seguro de las diferentes compañías aseguradoras establecen varios niveles de garantías que pueden suscribirse, un primer nivel de garantía obligatoria que cubre lo establecido por la normativa reguladora del seguro obligatorio de responsabilidad civil del cazador, a esta va añadida una póliza por daños materiales. Por esta póliza el asegurador se compromete a pagar las indemnizaciones pecuniarias que por daños corporales originados d a terceros, sean responsabilidad civil del cazador con armas asegurado causados con ocasión de cazar.

A la anterior se puede contratar una garantía de suscripción voluntaria que cubra los daños causados a animales o cosas propiedad de terceros durante la caza, los daños causados en competiciones autorizadas de tiro deportivo y no producidos por la acción de cazar, los daños producidos a terceras personas durante el montaje y limpieza de armas de caza no garantizados por la garantía de suscripción obligatoria o bien durante el traslado de las armas a/o desde el lugar de caza y los daños causados a terceros por quienes deba responder el cazador-asegurado (empleados, ojeadores, etc.) por los animales que se encuentren bajo la custodia de éstos en el momento de la práctica de la caza, incluidos los que sean propiedad del asegurado (se puede limitar el número de perros hasta un máximo de dos tres, etc.).

Además de garantías anteriores también podemos mencionar como garantías voluntarias adicionales, seguro de accidentes que cubre la indemnización al asegurado o sus beneficiarios en caso de muerte por accidente y/o invalidez total o parcial cuando esta ocurra durante la práctica de la caza o durante la estancia y desarrollo de la misma en los terrenos destinados a tal fin. Finalmente mencionar la posibilidad de suscripción de una garantía que cobra el riesgo del robo del arma propiedad del asegurado, por lo general siempre que dicha circunstancia ocurra dentro del interior del vehículo durante los desplazamientos. 
Este contrato de seguro obligatorio tiene la duración de un año prorrogable conforme a lo establecido por la Ley de contrato de seguro ${ }^{92}$ como excepción, el Reglamento ${ }^{93}$ permite establecer un plazo de duración inferior al año siempre que se corresponda con la duración de las licencias de caza temporales expedidas, en su caso por distintas Comunidades Autónomas.

Celebrado el contrato el cazador obtendrá el certificado de seguro que es la tarjeta acreditativa de que el cazador se encuentra en posesión del Seguro Obligatorio de Responsabilidad Civil ${ }^{94}$.

En caso de que se produzca un siniestro la declaración del mismo ha de cumplir los siguientes requisitos:

a) Se realizará por el tomador del seguro, o por el cazador asegurado.

b) El plazo para realizar la declaración del siniestro es de quince días desde que ocurrió el mismo o desde que se tuvo conocimiento del mismo $^{95}$.

c) La declaración ha de hacerse por escrito.

d) La notificación del siniestro ha de contener los siguientes datos: día y hora del accidente, circunstancias en que el accidente tuvo lugar, nombre, profesión y domicilio de las personas responsables del accidente y de los miembros del grupo de caza y datos de la víctima o víctimas.

e) Detalle de los daños causados por el accidente.

f) Nombre, profesión, empleo y domicilio de los testigos del siniestro.

\footnotetext{
${ }^{92}$ Ley 50/1980 de 8 de octubre de contrato de seguro artículo 22

"La duración del contrato será determinada en la póliza, la cual no podrá fijar un plazo superior a diez años. Sin embargo, podrá establecerse que se prorrogue una o más veces por un periodo no superior a un año cada vez.

Las partes pueden oponerse a una prórroga del contrato mediante una notificación escrita ala otra parte, efectuada con un plazo de dos meses de anticipación a la conclusión del periodo de seguro en curso.

Lo dispuesto en los párrafos precedentes no será de aplicación en cuanto sea incompatible con la regulación del seguro sobre vida”..

93 Artículo 5.

${ }^{94}$ El certificado de seguro tiene los siguientes datos: nombre del cazador, domicilio, denominación, domicilio y CIF de la entidad aseguradora, nombre del tomador del seguro si es diferente de la persona del cazador, clase de arma que se utiliza, periodo de validez del seguro, prima del seguro, firma y sello de la entidad aseguradora y número del certificado.

${ }^{95}$ Este plazo no se computa cuando haya imposibilidad de declarar.
} 
g) Autoridades que han tenido conocimiento del siniestro.

h) Facultativos o centros asistenciales que, en su caso, hayan atendido a las víctimas.

i) Cualesquiera otras circunstancias que se estimen de interés o que solicite el asegurador.

El Reglamento regula la responsabilidad concurrente que resulta cuando los daños hubieran sido causados por los integrantes de una partida de caza y no constare el autor de los mismos. En este caso responderán solidariamente como miembros de la partida los aseguradores de los cazadores que hubieran practicado el ejercicio de la caza en la ocasión y lugar en que el daño haya sido producido y que hubieran utilizado armas de la clase que originó el daño.

La víctima o sus derechohabientes tienen acción directa contra el asegurador del cazador causante del daño, o bien contra el Consorcio de Compensación de Seguros ${ }^{96}$, para reclamar la indemnización que les corresponda. Con independencia de ello pueden ejercer cuantas acciones legales les correspondan como consecuencia del siniestro.

La reclamación habrá de ir acompañada en todo caso de la notificación del siniestro y el certificado médico acreditativo de las lesiones sufridas.

${ }^{96}$ El Consorcio de Compensación de Seguros asumió mediante Real Decreto 731/1987 de 15 de mayo por el que se aprueba el Reglamento del Consorcio de Compensación de seguros, las funciones y competencias del antiguo Fondo de Garantía que había establecido la derogada Orden de 20 de julio de 1971. El consorcio es la entidad última que tiene que responder en materia aseguradora y entre sus funciones se encuentra el ejercicio de las competencias establecidas en la legislación respecto al seguro Obligatorio de Responsabilidad Civil del Cazador.

$\mathrm{El}$ artículo3을 establece entre las funciones del Consorcio "” $f$ ) Ejercer las competencias establecidas en la legislación respecto al Seguro Obligatorio de Responsabilidad Civil del Cazador”.

El Consorcio de Compensación de seguros, asumirá, dentro de los límites indemnizatorios fijados para el Seguro obligatorio de responsabilidad civil del cazador la contratación de la cobertura de riesgos no aceptados por las entidades aseguradoras y el pago de las obligaciones de dichas entidades declaradas en quiebra, suspensión de pagos o en situación de insolvencia estando sujetas a procedimiento de liquidación intervenida o asumida por la Comisión Liquidadora de Entidades Aseguradoras.

Por otra parte, con ocasión del ejercicio de la caza con armas y dentro de los mismos límites deberá indemnizar a las víctimas o sus beneficiarios de los daños corporales causados a las personas en España con ocasión del ejercicio de la caza con armas cuando el causante del daño no esté asegurado o sea desconocido; indemnizar los daños corporales producidos por arma de caza cuando no pudiera hacerse efectiva la prestación económica por los medios regulados en la legislación sobre seguro de responsabilidad del cazador de suscripción obligatoria. 
Con independencia del procedimiento judicial que proceda, la víctima o sus beneficiarios pueden convenir con el asegurador el importe de la indemnización ${ }^{97}$.

Transcurridos quince días desde la fecha de reclamación sin que el asegurador haya aceptado el siniestro, el reclamante puede dirigirse al Consorcio de Compensación de Seguros, que discrecionalmente puede anticiparlos importes correspondientes hasta el límite de lo establecido en el baremo y consecuentemente subrogarse en los derechos del beneficiario -víctima o derechohabiente- contra el asegurador.

El asegurador abonará la indemnización total que corresponda en el plazo máximo de diez días desde la aceptación de la reclamación y siempre que la cantidad sea líquida y determinada y se haya acreditado la legitimación de los reclamantes para percibirla ${ }^{98}$.

El asegurador o el Consorcio de Compensación de seguros ${ }^{99}$, pueden repetir de acuerdo con lo establecido en la Ley de contrato de seguro ${ }^{100}$ la acción de reclamación contra el causante del daño, contra el responsable civil subsidiario y contra ambos pero para que la acción de repetición pueda llevarse a efecto, éstos han de haber sido condenados por sentencia firme o sancionados por resolución administrativa que cause estado.

A este efecto, el Reglamento considera supuestos de daño o perjuicio causado a un tercero debido a conducta dolosa del asegurado, los ocasionados cazando sin haber obtenido licencia, o careciendo ésta de validez, con armas prohibidas, en época de veda o bajo influencia de bebidas alcohólicas, drogas

${ }^{97}$ A estos efectos sirve como criterio orientativo el baremo vigente de los riesgos de circulación El Real Decreto 63/1994 de 21 de enero derogó expresamente la Orden Ministerial de 14 de octubre de 1983 (Economía y Hacienda) sobre prestaciones y tarifas en el Seguro obligatorio del cazador.

\footnotetext{
${ }^{98}$ Por otra parte el asegurador no queda liberado de su obligación de pago por la alegación
} de falsedad, error u omisión en la proposición del seguro.

${ }^{99}$ El derecho de repetición del Consorcio de Compensación de Seguros podrá ejercitarse en los supuestos previstos en el artículo 8 del Reglamento y, además podrá dirigirse contra el causante del daño que no esté asegurado, desde que el consorcio haya procedido a indemnizar a las víctimas o a sus beneficiarios. (artículo 7.3 del Reglamento de responsabilidad civil del cazador).

${ }^{100}$ Artículo 76 de la Ley 50/1980 de 8 de octubre de contrato de seguro. 
tóxicas o estupefacientes; los ocasionados por hacer uso temerario de armas de caza en zonas de seguridad y aquellos en los que el causante del daño incurra en delito de omisión de socorro ${ }^{101}$.

El asegurador o el Consorcio podrán repetir la acción además en caso de pago indebido, cuando el hecho determinante del daño no se hubiese incluido en el ámbito de cobertura del seguro y cuando las víctimas o sus derechohabientes tampoco estuviesen incluidas en la cobertura del seguro.

\section{PROTECGIÓN, CONSERVACIÓN Y OTROS ASPECTOS DE LA CAZA}

Con el fin de regular el ejercicio de la caza se publica en el ámbito de cada Comunidad Autónoma una Orden General de vedas referida a las diferentes especies cinegéticas en dicha disposición se hace mención expresa de los terrenos cinegéticos zonas de régimen especial de caza, épocas, días y periodos hábiles, según las diferentes especies, modalidades y limitaciones generales en beneficio de las especies cinegéticas ${ }^{102}$.

El Reglamento de caza distingue entre la caza realizada con fines científicas y con fines industriales y comerciales. La primera precisa permiso especial otorgado con carácter personal y previo informe del centro científico que se halle directamente relacionado con el objeto de la investigación debiendo ser oído el Consejo Superior de Investigaciones Científicas.

Se entiende por explotación industrial de caza la orientada a la producción y venta de piezas de caza vivas o muertas, que podrá llevarse a cabo en granjas cinegéticas o en cotos privados de caza, considerándose incluidos en esta categoría los palomares de destinados a la cría de palomas zuritas o bravías.

Un aspecto que regula el Reglamento en su artículo 30 es el de los perros de caza disponiendo que los dueños de peros de caza deberán cumplir las prescripciones generales sobre tenencia, matriculación y vacunación de pe-

\footnotetext{
${ }^{101}$ Artículo 8 del Reglamento.

102 El artículo 25 del Reglamento de la Ley de caza de 1971 regula las vedas y otras medidas protectoras; el artículo 39 de la Ley de caza de Aragón, el artículo 20 de la Ley de caza de Asturias, el artículo 42 de la Ley de caza de Castilla y León regulan el sistema de vedas.
} 
rros, que por lo general suele establecerse mediante normativa municipal en las ordenanzas y bandos correspondientes ${ }^{103}$.

La rehala estará constituida por un máximo de cuarenta perros y un mínimo de dieciséis para la posesión de las mismas la legislación autonómica suele exigir un permiso especial ${ }^{104}$. El tránsito de perros por zonas de seguridad ha de realizarse con el control del animal por su propietario o quien lo represente, asimismo el paso por terrenos cinegéticos con perro de caza estará condicionado a los requisitos que establece el Reglamento según se trate de personas que posean o no licencia de caza ${ }^{105}$.

Por otra parte el Reglamento también establece la existencia de unas zonas de adiestramiento establecidas por la Administración ${ }^{106}$ o a través de los correspondientes municipios, los lugares y épocas así como las condiciones en que este adiestramiento en materia de caza podrá realizarse.

${ }^{103}$ La Ley 4/1997 de 25 de junio de caza de Galicia, dispone en su artículo 40.1 que "Los duenos de perros utilizados para la práctica de la caza quedarán obligados a cumplir las prescripciones generales que sobre tenencia, matriculación y vacunación dicten las autoridades competentes de conformidad con la Ley1/1993 de 13 de abril, de protección de animales domésticos y salvajes en cautividad".

${ }^{104}$ Ver artículo 40 de la Ley de caza de Galicia.

${ }^{105}$ Artículo 30-4 y 5. Las personas que no estén en posesión de licencia de caza se hallan obligadas a impedir que los perros que caminen bajo su custodia persigan o dañen las piezas de caza, sus crías y huevos.

Se considerará que el perro o perros vagan fuera del control de la persona encargada de su vigilancia en los siguientes casos:

Cuando los perros se alejen de la persona encargada de su cuidado más de $50 \mathrm{~m}$. en zonas abiertas desprovistas de vegetación, aún cuando permanezcan a la vista de esa persona.

Cuando los perros se alejen más de 15 metros en zonas donde la vegetación existente sea susceptible de ocultar al animal o a los animales de su respectivo cuidador, perdiendo el mismo su control.

En estos casos la persona responsable de la vigilancia será considerada infractora por cazar sin licencia, o en su caso, y teniendo en cuenta el lugar y la época será considerada infractora por cazar sin permiso o por cazar en época considerada de veda.

Las personas que se hallen en posesión de una licencia de caza válida para la utilización de perros, sólo podrán hacer uso de estos animales en terrenos donde por razón de época, especie y lugar estén facultados para hacerlo. En cualquier caso serán responsables de las acciones de los perros si las mismas transgredieran los preceptos legales destinados tanto a la conservación y protección cinegética, como a la seguridad de las personas, tanto propias del grupo de caza como ajenas.

106 En este caso la Administración autonómica. 
Finalmente señalar que la administración tiene encomendada la tarea de promoción y fomento de las razas de perros de caza estableciendo a estos efectos los libros orígenes de perros de caza españoles y los genealógicos correspondientes a este respecto tanto la Ley de caza y el Reglamento así como la normativa autonómica recogen este precepto ${ }^{107}$. El Real Decreto 391/1992 de 21 de abril por el que se regula el reconocimiento oficial de las organizaciones o asociaciones de criadores de animales de raza que lleven o creen libros genealógicos dispone entre otras cuestiones que por el Ministerio de Agricultura, Pesca y Alimentación, se determinarán los criterios básicos para la Reglamentación de los Libros y registros Genealógicos, con el fin de salvaguardar la pureza de las diversas razas. El Real Decreto 558/2001 de 25 de mayo por el que se regula el reconocimiento oficial de las organizaciones o asociaciones de criadores de perros de raza pura establece la regulación normativa referente a los requisitos que han de cumplir las asociaciones de perros de raza pura para llevar o crear libros genealógicos y los criterios de inscripción de los perros de raza pura en dichos libros o registros ${ }^{108}$. Este Real Decreto define las razas caninas españolas como "aquellas razas puras originarias de España, con prototipo y aptitudes definidas, ligadas tradicionalmente a la ganadería por sus actividades de pastoreo y manejo del ganado, la guarda, caza, compañia y otras utilidades ${ }^{109}$.

\section{CONTROL DE LA CAZA}

Dentro del término control de la caza incluimos los Registros administrativos y la vigilancia.

\footnotetext{
${ }^{107}$ El Artículo 28 de la Ley 1/1970 de caza, 30 del Reglamento de 1971 atribuyen al Ministerio de Agricultura esta competencia. El artículo 51 de la Ley de caza de Aragón establece que la Diputación General promoverá el fomento y mejora de las razas de perros de caza y ejercerá, asimismo, el control sobre las empresas y establecimientos que se dediquen a la cría, adiestramiento y comercio de perros de caza, en orden a garantizar sus condiciones de sanidad y pureza. El artículo 40.6 de la Ley de caza de Galicia establece que la Consejería de Agricultura, ganadería y Montes abrirá un libro-registro de razas caninas existentes en la Comunidad Autónoma.
}

108 Teniendo en cuenta -dice el preámbulo del Real Decreto- la gran diversidad de razas caninas y las implicaciones que éstas tienen en los diversos sectores de actividades, como la ganadería, el deporte, la caza, la sanidad, el ocio, o la seguridad pública.

109 Este Real Decreto contiene un anexo en el que se recogen las características de las diferentes razas de perros españoles 8 aspecto, carácter, tipo, partes del cuerpo, aptitudes, defectos, etc.). 
Por lo que hace a los Registros hay que señalar que la legislación estatal contempla diversos registros administrativos. El Catálogo Nacional de Especies amenazadas ${ }^{110}$ en el que se incluirán los animales o plantas cuya protección requiera de la administración la adopción de medidas específicas ${ }^{111}$. El Censo Nacional de Caza y Pesca ${ }^{112}$ dependiente del Ministerio de Medio Ambiente cuyo objeto es mantener la información más completa de las poblaciones, capturas y evolución genética de las especies autorizadas, incluyéndose los datos que faciliten las Comunidades Autónomas, fundamentados en la obligación que se impone a los cazadores de suministrar la correspondiente información a éstas. El Registro Nacional de Infractores de Caza y Pesca, dependiente del Ministerio de Medio Ambiente compuesto de los datos suministrados por los registros de infractores de las diferentes Comunidades Autónomas ${ }^{113}$.

La legislación autonómica prevé asimismo la creación de registros administrativos pudiendo mencionarse cuatro tipos: registros de fauna silvestre cinegético o no (catálogos de especies amenazadas, censos regionales de caza $)^{114}$; registros de te-

${ }^{110}$ Los artículos 31y 33.1 de la Ley 4/1989 de 27 de marzo determinan la imposibilidad de cazar las especies incluidas en dicho Catálogo. Ver el Real Decreto 439/1990 de 30 de marzo por el que se regula el Catálogo Nacional de especies Amenazadas (BOE núm. 82 de 5 de abril)..

${ }^{111} \mathrm{El}$ artículo 29 de la Ley 4/10989 dispone que las especies y subespecies o poblaciones que se incluyan en dichos catálogos deberán ser clasificadas en algunas de las siguientes categorías:

a) En peligro de extinción, reservada para aquellas cuya supervivencia es poco probable si los factores causales de su actual situación siguen actuando.

b) Sensibles a la alteración de su hábitat, referida a aquellas cuyo hábitat característico está particularmente amenazado, en grave regresión, fraccionado o muy limitado.

c) Vulnerables, destinada a aquellas que corren el riesgo de pasar a las categorías anteriores en un futuro inmediato si los factores adversos que actúan sobre ellas no son corregidos.

d) De interés especial, en la que se podrán incluir las que, sin estar contempladas en ninguna de las precedentes, sean merecedoras de una atención particular en función de su valor científico, ecológico, cultural o por su singularidad.

e) Por sentencia 102/1995 de 26 de junio (Suplemento BOE núm. 181 de 31 de julio; corrección en suplemento BOE núm. 284 de 28 de noviembre) se declaró la nulidad de la disposición adicional quinta de la Ley en cuanto declaraba básico este artículo.

112 Artículo 35.3 de la Ley 4/1989.

${ }^{113}$ El artículo 48.6 de la Ley de caza y 49.22 de su Reglamento disponían la existencia de un Registro General de Sancionados llevado en el Ministerio de Agricultura, que constituye el antecedente del Registro actual.

114 Art. 79 de la Ley de Caza de Aragón y 76 de la Ley de Caza de Castilla La Mancha. 
rrenos cinegéticos ${ }^{115}$, registros de infractores (en que se inscriben de oficio todas las personas sancionadas por resolución firme en materia de caza) ${ }^{116}$ y finalmente registro para actividades relacionadas con la caza (por ejemplo el Registro de Talleres de taxidermia de la Comunidad Autónoma de Castilla y León) ${ }^{117}$.

Respecto al personal de vigilancia La Ley de caza encomienda el cuidado y policía de la caza a las autoridades y sus agentes ${ }^{118}$, atribuyéndose la competencia a la Guardia Civil ${ }^{119}$ y a los distintos servicios de guardería que debían velar por el cumplimiento de la normativa denunciando cuantas infracciones llegasen a su conocimiento. Con el traspaso de competencias a las Comunidades Autónomas, se han creado cuerpos de guardería ${ }^{120}$ y de policía así como

${ }^{115}$ Artículos 57 y 58 de la Ley de Fauna silvestre; caza y pesca fluvial de Murcia.

${ }^{116}$ Artículo 85 de Ley de caza de Castilla y León.

${ }^{117}$ Artículo 61.3 de la Ley de caza de Castilla y León.

118 Artículo 40.

119 La vigilancia de la caza ha sido una de las funciones encomendadas a la benemérita desde su creación, así el artículo 30 párrafo tercero de su Reglamento de servicio de 9 de octubre de 1844, lo cual se contempló en disposición general primera de la Ley de caza de 1879 y la de la Ley de 1902. ABELLA J Manual de montes y guardería rural Madrid 1891.

Hoy en día la Guardia Civil dispone de un Servicio de Protección de la naturaleza

${ }^{120}$ El artículo 37.2 de la Ley 2/1989 de caza de Asturias dispone que en el ejercicio de las funciones, los guardas de la Comunidad Autónoma tendrán la consideración de agentes de la autoridad. El artículo 79.1 de la Ley 8/1990 de 21 de diciembre dispone que en el ejercicio de sus funciones los agentes del medio ambiente de la Comunidad Autónoma de Extremadura tendrán la consideración de agentes de la autoridad. El artículo 99 de la Ley foral 2/1993 de 5 de marzo Navarra de protección y gestión de la fauna silvestre y sus hábitats establece en su punto primero que el procedimiento sancionador respetará la presunción de no existencia de responsabilidad administrativa mientras no se demuestre lo contrario y en su punto tercero dispone que las actas de inspección o denuncias que se extiendan por los miembros de la Administración estarán dotadas de presunción de certeza respecto de los hechos reflejados en las mismas, salvo prueba en contrario. La Disposición adicional del mismo texto legal dispone que en el ejercicio de sus funciones los guardias de medio ambiente la Policía Foral y los técnicos del Departamento de Ordenación del Territorio y Medio Ambiente tendrán la consideración de agentes de la autoridad siempre que realicen funciones de inspección y control en cumplimiento de esta Ley foral y acrediten su condición mediante la correspondiente documentación.

El Decreto foral de Navarra 235/1992, que regula el personal funcionario de guardería, dispone en su artículo 2.3 que las actas de inspección y las denuncias que se extiendan por el personal de guardería en el ejercicio de sus funciones gozan de presunción de veracidad respecto de los hechos reflejados en las mismas, y hacen fe, salvo prueba en contrario. 
la existencia de policías locales por lo que la coordinación entre todos ellos resulta indudablemente necesaria. Los miembros de estos cuerpos, que no siempre tienen la condición de funcionarios siendo a veces personal laboral, en el ejercicio de sus funciones tendrán acceso a todo tipo de terrenos e instalaciones relacionados con la caza pudiendo entrar incluso en los terrenos rurales cercados para vigilar el cumplimiento de las normas sobre caza.

La vigilancia privada de los cotos ya se establecía en la Ley de caza ${ }^{121}$ que disponía que las personas adscritas a la vigilancia de aquellos que no formasen parte de un Cuerpo oficial de guardería deberían hallarse en posesión del título de Guarda jurado expedido por la autoridad gubernativa correspondiente teniendo en el ejercicio de su cargo la consideración de agentes auxiliares de la Guardia civil y del Servicio de Pesca continental, Caza y Parques nacionales. La normativa autonómica dando un paso hacia delante impone a los titulares de cotos de caza la obligación de contar con un servicio privado de vigilancia que podrá ser propio o contratado, individual o compartido, estando su número en función de la extensión del acotado pero debiendo ser en todo caso suficiente $^{122}$. Los guardas jurados tienen pues la condición de agentes auxiliares de la autoridad ${ }^{123}$.

\section{SISTEMA SANCIONADOR}

\subsection{Delitos y penas}

Respecto a la tipificación penal hay que señalar en primer lugar que el Código Penal aprobado por Ley orgánica 10/1995 de 23 de noviembre ha reducido el repertorio de delitos relativos a la caza pasando de nueve tipos (establecidos en la Ley 1/1970 de caza más el contenido en el artículo 507 del Código Penal anterior) a cuatro tipos establecidos en los artículos 33 a 3356 del Código Penal actualmente vigente.

${ }^{121}$ Artículo 40.2 y 44.2 del Reglamento.

122 Art. 83 Ley de caza de Extremadura; 78.3 de la Ley de caza de Aragón; 82 de la Ley de caza de Castilla-La Mancha: 92.1 de la Ley de Fauna silvestre, caza y pesca fluvial de Murcia y 70 de la Ley de caza de Castilla y León.

${ }^{123}$ La normativa autonómica también prevé la posibilidad de nombramiento de guardas honorarios de caza a propuesta de las sociedades de cazadores o de las federaciones de caza, debiendo recaer la designación en personas de acreditada moralidad y destacada ejecutoria cinegética o bien personas que hayan superado las pruebas correspondientes. 
Dentro del título referido a los delitos contra la ordenación del territorio y la protección del patrimonio histórico y del medio ambiente, dedica el capítulo IV a la protección de la flora y la fauna. El artículo $333^{124}$ del Código tipifica la acción de introducir especies de flora o fauna no autóctonas contraviniendo la legislación específica el contenido del tipo se justifica por la protección del medio ambiente natural.

El artículo 334.1 contiene más de un supuesto pues tipifica la acción de cazar especies amenazadas, el perjuicio y el comercio y tráfico con las mismas o con sus restos; el artículo 335 tipifica la caza no autorizada de especies no amenazadas; el 336 tipifica el empleo de veneno, explosivos y sustancias similares en la caza ${ }^{125}$.

La justificación normativa última de estos preceptos se hala en la propia Constitución española cuando en su artículo 45.2 dispone que "Los poderes públicos velarán por la utilización racional de todos los recursos naturales, con el fin de proteger y mejorar la calidad de la vida y defender y restaurar el medio ambiente, apoyándose en la indispensable solidaridad colectiva" en su virtud hay que reconocer que los atentados contra el medio ambiente han de tener en sus modalidades más graves una clara protección penal ${ }^{126}$.

\footnotetext{
${ }^{124}$ Artículo 333 El que introdujera o liberara especies de flora o fauna no autóctona, de modo que perjudique el equilibrio biológico, contraviniendo las Leyes o disposiciones de carácter general protectoras de las especies de flora o fauna, será castigado con la pena de prisión de seis meses a dos años o multa de ocho a veinticuatro meses".
}

125 Artículo 334. 1 "El que cace o pesque especies amenazadas, realice actividades que impidan o dificulten su reproducción o migración, contraviniendo las Leyes o disposiciones de carácter general protectoras de las especies de fauna silvestre, comercie o trafique con ellas o con sus restos será castigado con la pena de prisión de seis meses a dos años o multa de ocho a veinticuatro meses.

2 La pena se impondrá en su mitad superior si se trata de especies o subespecies catalogadas en peligro de extinción".

Artículo 335 "El que caceo pesque especies distintas a las indicadas en el artículo anterior, no estando expresamente autorizada su caza o pesca por las normas específicas en la materia, será castigado con la pena de multa de cuatro a ocho meses".

Artículo 336 "El que sin estar legalmente autorizado, emplee para la caza o pesca veneno, medios explosivos $u$ otros instrumentos o artes de similar eficacia destructiva para la fauna, será castigado con la pena de prisión de seis meses a dos años o multa de ocho a veinticuatro meses. Si el daño causado fuera de notoria importancia se impondrá la pena de prisión antes mencionada en su mitad superior".

${ }^{126}$ Hay autores que entienden que el medio ambiente sólo en muy contadas y excepcionales ocasiones ha de tener una salvaguardia en el ámbito penal debiéndose dejar este ámbito para las sanciones administrativas. MOREU CARBONELL, e. Relaciones entre el Derecho administrativo y el Derecho penal en la protección del medio ambiente REVISTA ESPAÑOLA DE ADMINISTRACIÓN PUBLICA núm. 87, 1995. 
El nuevo sistema de reducción del repertorio de delitos, ha supuesto la conversión de muchos de los delitos establecidos por la Ley de caza en meras infracciones administrativas al no haber sido incorporadas al texto legal del nuevo Código Penal y haber sido expresamente derogadas por éste ${ }^{127}$.

Además de los tipos mencionados, el Código establece una serie de reglas de aplicación, así el artículo 338 dispone que cuando las conductas definidas en el título afecten a algún espacio natural protegido se impondrán las penas superiores en grado a las respectivas previstas, esto supone un plus de protección por razón de la categoría especial del lugar donde se haya cometido el delito. El artículo 339 contiene una medida de prevención y otra de restitución, pues permite a los jueces adoptar cualquier medida cautelar necesaria para la protección de los bienes tutelados en este título y autoriza a imponer la restauración del daño a cargo del autor. También prevé que cuando el culpable hubiera procedido voluntariamente a restaurar el daño se aplique la pena inferior en grado a la prevista.

\subsection{Infracciones y sanciones administrativas}

En nuestro Derecho todo el sistema sancionador establecido por leyes especiales ha de hallarse fundamentado en los principios recogidos en la Constitución cuyo artículo $25^{128}$.

\footnotetext{
127 Disposición Derogatoria Única de la Ley Orgánica 10/1995 de 23 de noviembre, del Código Penal, I Quedan derogados:

Ley de 19 de septiembre de 1896 para la protección de los pájaros insectívoros.

Ley $1 / 1970$ de 4 de abril de caza. Los delitos y faltas previstos en dicha Ley, no contenidos en este Código, tendrán la consideración de infracciones administrativas muy graves, sancionándose con multa de cincuenta mil a quinientas mil pesetas y retirada de la licencia de caza, o de la facultad de obtenerla, por un plazo de dos a cinco años".

128 Artículo 25 de la Constitución.1 Nadie puede ser condenado o sancionado por acciones $u$ omisiones que en el momento de producirse no constituyan delito, falta o infracción administrativa, según la legislación vigente en aquel momento.

2.Las penas privativas de libertad y las medidas de seguridad estarán orientadas hacia la reeducación y reinserción social y no podrán consistir en trabajos forzados. El condenado a pena de prisión que estuviere cumpliendo la misma gozará de los derechos fundamentales de este Capítulo, a excepción de los que se vean expresamente limitados por el contenido del fallo condenatorio, el sentido de la pena y la Ley penitenciaria. En todo caso, tendrá derecho aun trabajo remunerado y a los beneficios correspondientes de la Seguridad Social, así como al acceso a la cultura y al desarrollo integral de su personalidad.

3. La Administración civil no podrá imponer sanciones que, directa o subsidiariamente impliquen privación de libertad.
} 
contiene según ha declarado el Tribunal Constitucional una doble garantía la primera relativa al principio de seguridad jurídica en los ámbitos privativos de libertad individual en el ámbito penal y administrativo sancionador incorporando la predeterminación normativa de las conductas ilícitas y de las sanciones correspondientes y la segunda de carácter formal relativa al rango necesario de las normas tipificadoras por lo que el término legislación vigente es expresivo de una reserva de Ley en materia sancionadora ${ }^{129}$.

Además de la Ley de caza de 1970 la normativa autonómica ha regulado esta materia habiéndose realizado un traspaso de la potestad sancionadora a las Comunidades Autónomas. De todos modos la legislación autonómica ha de ajustarse a las exigencias de la Constitución en materia sancionadora, así como respetar la competencia exclusiva del Estado en materia penal ${ }^{130}$, sobre legislación de armas ${ }^{131}$, y la legislación básica del Estado en materia de medio ambiente y sobre procedimiento administrativo común ${ }^{132}$. El Tribunal Constitucional ha declarado sobre esta materia que las normas sancionadoras autonómicas no pueden introducir tipos ni prever sanciones que difieran, sin fundamento razonable, de los ya recogidos en la normativa válida para todo el territorio, no obstante las Comunidades Autónomas pueden establecer la sanción que consideren más adecuada en su competencia de ordenación sustantiva de la caza ${ }^{133}$. Hay que señalar que la legislación autonómica no variado en lo sustancial el sistema de sanciones en la caza.

Por lo que se refiere a los principios del derecho sancionador en materia de caza comenzaremos por el de legalidad que como hemos visto recoge la Constitución ${ }^{134}$, que supone un reserva de ley formal estatal o autonómica para el establecimiento de infracciones y sanciones administrativas pudiéndose

\footnotetext{
${ }^{129}$ STC $42 / 1987$ FJ. $2^{\text {o }}$ y STC $101 / 1988$ FJ. $3^{\circ}$.

${ }^{130}$ Artículo 149.1. $6^{\mathrm{a}}$ de la Constitución.

${ }^{131}$ Artículo 149..26 a de la Constitución.

132 Artículo 1491-6 ${ }^{-\underline{a}}$ y $26^{\text {a }}$ de la Constitución y los principios contenidos en las disposiciones del título IX de la Ley 30/1992 de 26 de noviembre de Régimen jurídico de las Administraciones Públicas y del procedimiento administrativo común, relativo a la potestad sancionadora.

133 STC 87/1985 de 16 de julio FJ. $8^{\circ}$.

134 Artículo 25.1 Ver artículo 129.1 de la Ley 30/1992.
} 
introducir especificaciones o graduaciones a las infracciones y sanciones mediante normas reglamentarias no pudiendo esto constituir nuevos tipos ni alterar la naturaleza de los que la Ley haya establecido ${ }^{135}$.

Respecto a la tipicidad hay que señalar que es requisito elemental Derecho sancionador en cuya virtud sólo "constituyen infracciones administrativas las vulneraciones del Ordenamiento Jurídico previstas como tales infracciones por una Ley"136. La Ley de caza de 1970 recoge este principio disponiendo que "El incumplimiento de las prescripciones de esta Ley podrá ser constitutivo de delito, falta o infracción administrativa cuando asi estuviere calificado en la misma"137.

Tanto la normativa estatal como la autonómica establecen amplios repertorios de infracciones ${ }^{138}$ en su mayor parte coincidentes, por otra parte también contienen cláusulas residuales definiendo infracciones administrativas por remisión a las obligaciones y prohibiciones establecidas en las propias leyes ${ }^{139}$. El problema que se plantea es saber si esta tipificación por remisión res-

135 Artículo 129.3 de la Ley 30/1992.

El Tribunal Supremo ha declarado que al configurar como grave una infracción administrativa mediante el Real Decreto 1095/1989 y no mediante la Ley 4/1989 de 27 de marzo (que simplemente establece criterios orientativos para la calificación de gravedad de las infracciones) se había infringido el artículo 25 de la Constitución. En consecuencia declaraba que esta disposición constitucional exige además de la de definición por ley de las infracciones y las sanciones, la correspondencia entre ambas y la calificación de su gravedad. STS. de 9 de noviembre de 1993 y de 14 de marzo de 1996.

136 Artículo 129.1 de la Ley 30/1992.

${ }^{137}$ Artículo 41 de la Ley 1/1970 de caza.

138 Por ejemplo la Ley 8/1990 de 21 de diciembre de caza de Extremadura contiene en su título XI De las infracciones y sanciones cerca de un centenar de infracciones (34 leves, 27 graves y 8 muy graves).

139 Artículo 46 de la Ley de caza de 1970 "Constituirá infracción administrativa de caza toda acción u omisión voluntaria que vulnere las prescripciones de esta Ley o del Reglamento que se dicte para su aplicación, y no estén comprendidas en los artículos 42 y 43 de la misma".

El artículo 84 de la Ley 2/1993 de 15 de julio de caza de Castilla la Mancha establece que "Las acciones $u$ omisiones que infrinjan lo establecido en la presente Ley darán lugar a responsabilidad de naturaleza administrativa, sin perjuicio de la exigible en vía penal o civil'.

El artículo 85 de la Ley 8/1990 de 21 de diciembre de caza de Extremadura establece que "Constituye infracción y genera responsabilidad administrativa toda acción u omisión que suponga incumplimiento de lo preceptuado en esta Ley y en las disposiciones que la desarrollen, sin perjuicio de la que fuera exigible en la vía penal o civil". 
peta o no el principio de tipicidad que hemos descrito, en la doctrina hay diversas opiniones, pareciendo lo más adecuado que como norma general las infracciones más graves han de hallarse definidas en todo caso por Ley, pudiendo referirse la remisión a infracciones de carácter leve.

Dentro del tercer principio hemos de señalar que la responsabilidad administrativa requiere para ser efectiva la culpabilidad del imputado ${ }^{140}$.

Respecto al valor probatorio de las denuncias del personal de control ${ }^{141}$, hay que diferenciar casos en que tenga la condición de agente de la autoridad y casos que no la tenga.

Nuestro ordenamiento jurídico reconoce un valor cualificado a las denuncias que, en el ejercicio de sus funciones, formulen los agentes de la autoridad así lo establece la Ley 30/1992 de 26 de noviembre de Régimen jurídico de las Administraciones Públicas y del Procedimiento administrativo común amparando una presunción de veracidad que admite prueba en contrario en el ámbito del procedimiento sancionador. Para que tenga lugar esta presunción de veracidad han de cumplirse tres condiciones:1) los hechos han de ser constatados por funcionarios públicos, con esa condición ${ }^{142}$;2) Estos funcionarios han de tener reconocida la condición de autoridad por una nor-

${ }^{140}$ Artículo 130 de la Ley 30/1992.

${ }^{141}$ Esta materia se halla a su vez relacionada con el principio constitucional de presunción de inocencia establecido en la Constitución (artículo 24.2) que ha recogido la Ley 30/1992 en su artículo 137.1:

"1. Los procedimientos sancionadores respetarán la presunción de no existencia de responsabilidad administrativa mientras no se demuestre lo contrario.

2. Los hechos declarados probados por resoluciones judiciales penales firmes, vincularán a las administraciones Públicas respecto de los procedimientos sancionadores que se substancien.

3. Los hechos constatados por funcionarios a los que se reconoce la condición de autoridad, y que se formalicen en documento público observando los requisitos legales pertinentes, tendrán valor probatorio sin perjuicio de las pruebas que en defensa de los respectivos derechos o intereses puedan señalar o aportar los propios administrados.

4. Se practicarán de oficio o se admitirán a propuesta del presunto responsable cuantas pruebas sean adecuadas para la determinación de hechos y posibles responsabilidades.

Sólo podrán declararse improcedentes aquellas pruebas que por su relación con los hechos no puedan alterar la resolución final a favor del presunto responsable".

${ }^{142}$ Lo cual excluye a los empleados públicos que carezcan de la condición de funcionarios, así como a las personas que cumpliendo funciones de vigilancia y control, no se hallen al servicio directo de la Administración. 
ma y 3) las denuncias han de estar formalizadas en documento público de acuerdo con la Ley ${ }^{143}$.

Por todo ello las denuncias, han de tener la consideración del primer medio de prueba que no exonera a la Administración de toda prueba respecto a los hechos y cuyo valor o eficacia, según ha declarado el Tribunal Constitucional $^{144}$, ha de medir se a la luz del principio de la libre valoración de la prueba. Es decir que, la convicción sobre la verosimilitud de los hechos ha de ser consecuencia no sólo de la apreciación de los agentes denunciantes sino de la totalidad de las circunstancias que concurran en el caso lo cual permitirá apreciar la realidad de la comisión de los hechos.

Respecto al sistema de sanciones hay que señalar que en materia de caza la sanción principal es la multa, estando su cuantía en función de la gravedad de la infracción ${ }^{145}$ oscilando entre las 250 y 50.000 pesetas en la Ley de caza y entre 5.000 y 10.000 pesetas para infracciones leves y 15 a 50 millones para las muy graves.

A la sanción económica va acompañada en algunos supuestos de modo necesario en otros de manera potestativa la aplicación de medidas accesorias como son la revocación del permiso de caza, la inhabilitación para su obtención durante un periodo de tiempo o la anulación de la declaración de acotado. Las medidas accesorias sólo pueden ser impuestas si el comportamiento ha sido objeto de la sanción principal pues el Tribunal Supremo ha considerado que cuando ante la comisión determinadas infracciones graves en materia de caza una Resolución administrativa aplica una sanción accesoria no preceptiva en lugar de imponer la sanción principal de multa se vulnera el principio de legalidad ${ }^{146}$.

\footnotetext{
143 "Tienen la consideración de documento público administrativo los documentos válidamente emitidos por los órganos de las Administraciones Públicas”. Artículo 46.4 de la Ley 30/1992 de 26 de noviembre.

144 STC 76/1990 de 26 de abril FJ $8^{\circ}$, B.

Por otra parte el mismo fundamento jurídico de la mencionada sentencia señala que la denuncia sólo tiene valor probatorio respecto de los hechos comprobados directamente por el funcionario, por lo que otros aspectos como calificaciones jurídicas, juicios de valor o meras opiniones que los agentes consignen en las actas y diligencias carecerán de ese valor probatorio.

${ }^{145}$ La normativa autonómica al respecto ha actualizado el importe de las multas que se hallaba totalmente desfasado.

146 STS. De 9 de noviembre de 1993.
} 
Si bien el comiso de los instrumentos usados en la comisión de la infracción así como de las piezas de caza obtenidas ${ }^{147}$ puede considerarse como una medida accesoria no obstante se trata propiamente de una medida cautelar inmediata que se adopta a la vista de los primeros indicios de la comisión infractora anticipándose a la prueba y por lo tanto a la imposición de la sanción ${ }^{148}$.

El principio de proporcionalidad de las sanciones recogido en la Ley de Régimen Jurídico y Procedimiento administrativo común ${ }^{149}$ requiere que se guarde un grado aceptable de adecuación entre la gravedad del hecho constitutivo de la infracción y la sanción aplicada, en su virtud la graduación de las sanciones habrá de hacerse tomando en consideración la intencionalidad, reiteración, naturaleza de los perjuicios causados así como la reincidencia ${ }^{150}$.

Las sanciones administrativas pueden acompañarse con la exigencia al infractor de reparación de la situación alterada por él así como loa indemnización por los daños y perjuicios causados cuyo importe es en muchas ocasiones superior al de la multa

\footnotetext{
${ }^{147}$ Ley 1/1970 de caza artículo 50 Comisos.

Todo delito, falta o infracción administrativa de caza llevará consigo el comiso de la caza, viva o muerta, que fuere ocupada.

1. A la caza viva se le dará el destino que se señale reglamentariamente, de acuerdo con las circunstancias que concurran en el hecho; tratándose de caz muerta se entregará, mediante recibo, en un centro benéfico local y, en su defecto, a la alcaldía que corresponda con idénticos fines.

2. Los lazos, perchas, redes y artificios empleados para cometer la infracción serán decomisados subastándose públicamente los de uso i legal tan pronto hayan servido como pruebas de la denuncia. Tratándose de perros, de aves de presa, de reclamos de perdiz o de hurones, el comiso será sustituido por el abono de una cantidad en papel de pagos al Estado, que no podrá exceder de 1.000 pesetas por cada uno de estos animales.

Ver artículo 47 de la Ley de caza de Asturias; 93.b) y c) de la Ley de caza de Extremadura, 66 y 67 de la Ley de caza de Aragón y 102 de la Ley de Fauna silvestre, caza y pesca fluvial de Murcia.

148 El Consejo de Estado ha considera que el comiso pierde su justificación tan pronto como decae la infracción administrativa y no se impone sanción, en cuyo caso la actividad administrativa que puede haber generado perjuicios ha de ser objeto de responsabilidad por la Administración. Dictamen del Consejo de Estado 984/1992 de 17 de septiembre.

149 Artículo 131.3.

150 También pueden tenerse en cuenta como criterios de graduación de las sanciones el ánimo de lucro y la cuantía del beneficio obtenido con la comisión de la infracción, el cargo o función del infractor o su especial conocimiento por razones profesionales o académicas, la colaboración con la Administración en el esclarecimiento de los hechos y la restitución del bien o bienes tutelados.
} 


\section{EPÍlOOGO}

En el presente trabajo hemos examinado los principales aspectos de la regulación de la caza en España. A pesar de que varias Comunidades Autónomas han desarrollado esta materia mediante legislación propia como competencia exclusiva, todavía resulta de general aplicación y de indudable término referencial la Ley de 1970 y su Reglamento de desarrollo.

Por otra parte la normativa autonómica aprobada ha venido a cohonestarse adecuadamente con la legislación estatal vigente lo que demuestra su calidad técnica, esto junto a la nueva normativa sobre espacios naturales protegidos y de protección de la flora y fauna silvestres, así como la de normas específicas como el seguro obligatorio de responsabilidad civil del cazador configura un corpus normativo que constituye el Derecho positivo español sobre caza.

Finalmente señalar que en este trabajo no se ha tratado la materia sanitaria y de comercialización de productos de la caza por tratarse de normativa integrada conceptualmente en el bloque de normas sanitarias o normas sobre comercialización.

\section{APÉNDICE: NORMATIVA GENERAL SOBRE LA CAZA EN ESPAÑA}

\section{I) LEGISLACIÓN DEL ESTADO}

- Constitución española, artículos 148 y 149.

- Ley 4/1989 de 27 de marzo de conservación de espacios naturales y de la flora y la fauna silvestres.

- Ley 1/1970 de 4 de abril de caza.

- Decreto 506/1971 de 25 de marzo (Agricultura) aprueba el Reglamento para la ejecución de la Ley de caza.

- Real Decreto 1095/1989 de 8 de septiembre por el que se declaran las especies objeto de caza y pesca y se establecen normas para su protección.

- Real Decreto1118/1989 de 5 de septiembre por el que se determinan las especies objeto de caza y pesca comercializables y se dictan normas al respecto.

- Real Decreto 63/1994 de 21 de enero por el que se aprueba el Reglamento de seguro de responsabilidad civil del cazador, de suscripción obligatoria. 
- Real Decreto 2044/1994 de 14 de octubre por el que se establecen las condiciones sanitarias y de sanidad animal aplicables al sacrificio de animales de caza silvestre y a la producción y comercialización de sus carnes.

\section{LEGISLACIÓN DE LAS COMUNIDADES AUTÓNOMAS}

- ANDALUCÍA: Ley 8/2003 de la flora y la fauna silvestres.

- ARAGóN: Ley 12/1992 de 10 de diciembre de caza Aragón; Decreto 108/95 de 9 de mayo, Reglamento caza de Aragón.

- ASTURIAS: Ley 2/1989 de 6 de junio de caza de Asturias; Decreto 24/91 de 7 de febrero aprueba Reglamento de caza de Asturias.

- CASTILLA Y LEÓN: Ley 4/1996 de 12 de julio de caza de Castilla y León.

- CASTILla LA MANCHA: Ley 2/1993 de 15 de julio de caza de Castilla la Mancha; Decreto 14/96 de 9 de diciembre aprueba Reglamento de aplicación de la Ley de caza.

- EXTREMADURA: Ley 8/1990 de 21 de diciembre de caza de Extremadura.

- MURCIA: Ley 7/2003 de 12 de noviembre de caza y pesca fluvial de la Región de Murcia.

- NAVARRA: Ley Foral 2/1993 de 5 de marzo de protección y gestión de la fauna silvestre y sus hábitats; Decreto Foral 390/93 de 27 de diciembre, Reglamentos de caza de Navarra.

- PAÍS VASCO: Ley 1/1989 de 13 de abril de caza y pesca fluvial; Ley 16/1994 de 30 de junio de conservación de la naturaleza del País Vasco.

- GALICIA: Ley 4/1997 de 25 de junio de caza de Galicia.

- CANTABRIA: Ley 3/1992 de 18 de marzo de Protección de los animales.

\section{ÓRDENES AUTONÓMICAS DE VEDAS DE CAZA}

Andalucía: Orden de 12.6.2003 por la que se modifica la de 22 de mayo de 2000 que fija vedas y periodos hábiles de caza en el territorio de la Comunidad Autónoma de Andalucía. (BOJA de 2 de julio de 2003).

Aragón: Orden de 7 de julio de 2003 Departamento de Medio Ambiente. (Boletín Oficial de Aragón de 25 de julio 2003).

Asturias: Resolución de 11 de febrero de 2003 de la Consejería de Medio Ambiente (Boletín Oficial del Principado de Asturias de 27 de febrero). 
Baleares: Orden de 9 de junio de 2003 de la Consejería de Medio Ambiente (Boletín Oficial de Baleares de 19 de junio).

Canarias: Orden de 25 de junio de 2001 de la Consejería de Política Territorial y Medio Ambiente (Boletín Oficial de Canarias núm. 80 de 29 de junio).

Cantabria: Orden 43/2003 de 14 de mayo, de la Consejería de Ganadería, Agricultura y Pesca (Boletín Oficial de Cantabria de 26 de mayo).

Castilla-La Mancha: Orden de 14 de mayo de 2003, de la Consejería de Agricultura y Medio Ambiente (Diario Oficial de Castilla-La Mancha de 28 de mayo).

Castilla y León: Orden MAM/869/2003 de 26 de junio de la Consejería de Medio Ambiente (Boletín Oficial de Castilla y León 30 de junio de 2003).

Cataluña: Resolución MAB/2307/2003 de 1 de julio del Departamento de Medio Ambiente (Diario Oficial de la Generalidad de Cataluña de 27 de julio).

Extremadura: Orden de 30 de abril de 2003, de la Consejería de Agricultura y Medio Ambiente. (Diario Oficial de Extremadura de 8 de mayo de 2003).

Galicia: Orden de 30 de julio de 2003 de la Consejería de Medio Ambiente. (Diario Oficial de Galicia 11 de agosto de 2003).

Madrid: Orden 790/2003 de 28 de abril de la Consejería de Medio Ambiente (Boletín oficial de la Comunidad de Madrid de 5 de mayo).

Murcia: Orden de 6 de junio de 2003, de la Consejería de Agricultura, Agua y Medio Ambiente (Boletín oficial de la Región de Murcia núm. 120 de 25 de mayo).

Navarra: Orden Foral de 22 de junio de 2001, de la Consejería de Medio Ambiente, Ordenación del territorio y Vivienda. (Boletín Oficial de Navarra núm. 81 de 4 de julio).

La Rioja: Orden 2/2003 de 21 de julio de la Consejería de Turismo, Medio Ambiente y Política Territorial. (Boletín Oficial de La Rioja de 29 de julio).

Valencia: Orden de 6 de junio de 2001, de la Consejería de Medio Ambiente.(Diario Oficial de la Generalidad Valenciana núm. 4.024 de 19 de junio).

País Vasco: Orden Foral 1018/2003, del Departamento de Agricultura y Medio Ambiente. (Boletín Oficial del territorio Histórico de Álava de 23 de julio).

Orden Foral de 15 de junio de 2003, del departamento de Agricultura y Medio Ambiente. (Boletín Oficial de Guipúzcoa de 29 de julio). 
Orden Foral 3504/2003, del Departamento de Agricultura.(Boletín Oficial de Vizcaya 21 de julio de 2003).

Comunidad Valenciana: Orden de 16 de junio de 2003 de la Consellería de Medio Ambiente (DOGV 17.6.2003).

\section{BIBLIOGRAFÍA}

ABELLA POBLET, M. Manual del Derecho de caza Madrid 1973.

BOQUERA OLIVER, J.M. Aspectos administrativos de la Ley de caza REVISTA DE ESTUDIOS DE LA VIDA LOCAL núm. 177.

CUENCA ANAYA, F. Caza y medio ambiente Derecho Agrario y Alimentario núm. 26.

DE LOS MOZOS J.L. Precedentes históricos y aspectos civiles del Derecho de caza REVISTA DE DERECHO PRIVADO 1972.

GARCÍA CANTERO, G. Notas sobre la Ley de caza de 4 de abril de 1970 Jornadas Italo-españolas de Derecho Agrario Valladolid: 1976.

GARCÍA LAVERNIA J. Y FLORES LÓPEZ, F. Derecho español de caza REVISTA DE DERECHO JUDICIAL 1965.

GRAU FERNÁNDEZ, S. Derecho de caza normativa actual en España Madrid: 1973.

LÓPEZ RAMÓN, F. La protección de la fauna en el Derecho español Sevilla: 1980.

MARTÍN MATEO, R. La protección de la fauna y la flora REVISTA VASCA DE ADMINISTRACIÓN PÚBLICA núm. 41.

IDEM Manual de Derecho ambiental Madrid 1995.

MUÑOZ GOYANES, G. Comentarios sobre la caza en España MONTES núm. 151.

PELLISE PRATS, B. CAZA Nueva Enciclopedia Jurídica tomo III Barcelona: 1951. 
PONTE ESCARTÍN, G. El derecho a cazar Barcelona: 1902.

SÁNCHEZ GASCÓN, A. El Derecho de caza en España. De los terrenos y de las piezas de caza Madrid: 1988.

IDEM Leyes de caza en España Madrid:1998. 